\title{
Análise comparativa e aspectos ecológicos da reação de alarme em duas espécies de Mimagoniates (Ostariophysi, Characidae, Glandulocaudinae)
}

\author{
Luiz Fernando Duboc
}

Grupo de Pesquisas em Ictiofauna, Museu de História Natural Capão da Imbuia. Rua Benedito Conceição 407, Capão da Imbuia, 82810-080 Curitiba, Paraná, Brasil.E-mail: Ifduboc@uol.com.br

\begin{abstract}
Comparative analysis and ecological aspects of the alarm reaction in two species of Mimagoniates (Ostariophysi, Characidae, Glandulocaudinae). A new method for analysis of alarm reaction of fishes is proposed by the study of "Schreckreaktion" from Mimagoniates lateralis (Nichols, 1913) and Mimagoniates microlepis (Steindachner, 1876), which results were discussed on species ecology context. The method is based on Cartesian interpretation of the behaviour, where three distinct experimental series are analyzed in segmented way on horizontal and vertical axes. Data were analyzed by non-parametric statistics and longitudinal data analysis, which allow the time series graphic analyses, and interpreted together the crowding states of the schools by use of indexes. The conjugated analysis of all factors allowed a less subjective measurement of the reaction intensity. The results obtained from the horizontal axis weren't conclusive and the vertical axis demonstrated significant behavioural differences between series and species. Mimagoniates lateralis (Nichols, 1913) showed more stressed and crowded individuals, with schools trending to bottom, while M. microlepis showed more fitness to experimental conditions. Both species exhibited clear alarm reaction, and $M$. lateralis showed it three times more intense, presenting larger cohesion of the schools and larger period and amplitude of reaction, what is coherent with its status of endemic and threatened species.
\end{abstract}

KEY WORDS. Alarm intensity; behaviour; ecology; fishes; methodology; schreckreaktion.

RESUMO. É proposta uma nova metodologia para o estudo das reações de alarme em peixes, utilizada aqui no estudo da "Schreckreaktion" de Mimagoniates lateralis (Nichols, 1913) e Mimagoniates microlepis (Steindachner, 1876), cujos resultados foram contextualizados à ecologia das espécies. $O$ método baseia-se na interpretação cartesiana do comportamento, em que três baterias experimentais distintas são analisadas de forma segmentada nos eixos horizontal e vertical. Os dados foram analisados por estatística não-paramétrica e pela análise de dados longitudinais, a qual permite a interpretação gráfica de séries temporais, e integrados com os estados de agregação dos cardumes pelo uso de índices. A análise conjugada de todos os fatores permitiu uma mensuração menos subjetiva da intensidade de reação. Os resultados para o eixo horizontal não foram conclusivos e os do eixo vertical demonstraram significativas diferenças comportamentais entre baterias e espécies. Mimagoniates lateralis (Nichols, 1913) apresentou indivíduos mais estressados e agregados, com cardumes mais ao fundo, enquanto M. microlepis aparentou maior adaptabilidade às condições experimentais. Ambas as espécies demonstraram reação de alarme nítida, sendo que $M$. Iateralis a apresentou cerca de três vezes mais intensa, em que demonstrou maior coesão dos cardumes e maiores período e amplitude de reação, o que é coerente com seu status de espécie endêmica e ameaçada.

PALAVRAS-CHAVE. Comportamento; ecologia; intensidade do alarme; metodologia; peixes; schreckreaktion.

Os sinais de alarme estão difundidos entre os animais de hábitos sociais e são encontrados sob as mais variadas formas (SMITH 1992). As reações de alarme são especializações adaptativas comportamentais apresentadas por animais de hábito social, as quais visam à proteção contra predadores (EDMUNDS 1974). Para isso são utilizados os sentidos do olfato, paladar, tato, audição, visão e sistema acústico-lateral, bem como subs- tâncias químicas, tais como feromônios (substâncias que afetam membros receptores da mesma espécie do emissor), alomônios (substâncias que afetam membros receptores de outras espécies em benefício do emissor) ou cairomônios (substâncias que afetam membros receptores de outras espécies em benefício do receptor). Todos estes sistemas podem agir isoladamente ou integrados em diversas variações, relativas aos res- 
pectivos nichos ecológicos e suas adaptações (SмITH 1982). Reações de alarme a substâncias diluídas na água são encontradas desde Cnidaria à Amphibia (Pfeiffer 1963a, 1966, Howe \& SHeikH 1975, Johnson et al. 1985, Hews 1988, Madison et al. 2002, Marvin et al. 2004), com uma revisão mais atualizada sendo fornecida por Chivers \& SMith (1998). Os demais vertebrados, tais como répteis (Pfeiffer 1963a), aves (Ragusa-Netto 2000) e mamíferos (SHERman 1977) utilizam outros sentidos na complementação e/ou substituição dos sistemas de alarme. Muitos compõem efeitos integrados com a audição e a visão, e podem sofrer diversos graus de modulação ambiental.

O trabalho aqui apresentado enfoca o estudo da reação de alarme encontrada nos peixes ósseos, em especial o tipo encontrado nos Ostariophysi. A mais completa revisão dos estudos das reações de alarme em peixes foi realizada por Pfeiffer (1977), parcialmente atualizada por CHIVERS \& SMITH (1998).

Ostariophysi (Teleostei, Actinopterygii, Osteichthyes) é o grupo de peixes que predomina nas drenagens de água doce de todo o mundo (exceto Antártica, Groenlândia e Nova Zelândia). Esta superordem está na base da irradiação dos Euteleostei (MoYLE \& СЕCH 1988), representando mais de $25 \%$ de toda a ictiofauna conhecida hoje e cerca de $65 \%$ de todos os peixes de água doce (NELSON 2006). A importância deste grupo de peixes nas águas doces Neotropicais é marcada por sua diversidade, abundância e miniaturização (WEITZMAN \& VARI 1988), onde constitui mais de 85\% da ictiofauna da América do Sul (Lowe-McConnell 1987, CASTro 1999) em grande diversidade, com mais de 1649 espécies formalmente descritas de Siluriformes (FERRARIs \& ReIs et al. 2005), 1460 de Characiformes, 136 de Gymnotiformes, e ainda inúmeras espécies desconhecidas e/ou não descritas (ReIs et al. 2003). Assim, outros estudos como os de comportamento e de ecologia estão em estágio ainda muito incipiente (BÖHLKE et al 1978, CASTRO 1999).

Os ostariofisos possuem um tipo peculiar de reação de alarme como adaptação. Tal reação foi pioneiramente registrada pelo etólogo austríaco Karl von Frisch (prêmio Nobel de 1973 por seus trabalhos de descrição da dança das abelhas) em cardumes do ciprinídeo europeu Phoxinus phoxinus (Linnaeus, 1758) (Cyprinidae). Uma reação de alarme foi induzida de modo acidental durante estudos sobre as atividades auditivas dos peixes, nos quais o cardume estudado reagiu com uma nítida reação de "susto" após a introdução de um indivíduo recém-operado no aquário (Frisch 1938). Este tipo de reação de alarme foi denominado "Schreckreaktion", do alemão: "Schreck" = susto + "Reaktion" = reação (FRIsch 1941), e vem sendo estudado desde então como o sistema de alarme dos Ostariophysi (Pfeiffer 1963a, 1977, 1982, SMith 1982, 1986, 1992). Frisch (1941) concluiu que neste tipo de sistema o alarme é ativado pela percepção olfativa (e não gustativa) da substância de alarme, denominada por ele de "Schreckstoff", do alemão: "Schreck" = susto + "Stoff" = substância.

A substância de alarme é produzida e armazenada em células claviformes especiais da epiderme, as células de substância de alarme, as quais foram inicialmente identificadas e descritas por Pfeiffer (1960), que as denominou "Schreckstoffzellen", do alemão: "Schreck" = susto + "Stoff" = substância + "Zellen" = célula. Deduz-se que tal substância seja constituída por um conjunto variável de compostos complexos contendo óxido nítrico [NO] como grupo funcional, o qual é percebido pelos peixes de forma variável mas com reação específica. O mais provável é que seu principal constituinte seja a base púrica 3(N)-Óxido de hipoxantina, pois é o composto que apresenta a maior eficiência na indução da reação de alarme (PFeIfFer et al. 1985, SMith 1986, BRown et al. 2000, 2003).

A "Schreckreaktion" sensu Pfeiffer (1967) será aqui interpretada no sentido ampliado por SMITH (1992), para o qual a reação de alarme (RA = "Schreckreaction") é a exibição de um conjunto espécie-específico ou populacional de atitudes relacionadas à defesa contra a predação e o canibalismo (FrISCH 1938, 1941, Schutz 1956, Pfeiffer 1962, 1963a, 1974, 1977, Sмith 1977, 1982, 1986, 1992, Giaquinto \& Volpato 2005, Volpato et al. 2006). A RA ocorre apenas de forma involuntária, pela ocorrência de injúrias na pele de algum indivíduo. Isto faz com que as células de substância de alarme (CSA = "Schreckstoffzellen") sejam rompidas (ChIVERs \& SMITH 1998) e liberem a substância de alarme (SA = "Schreckstoff") no meio. A percepção olfativa da SA pelos membros mais próximos da espécie dá a partida na RA, a qual é então irradiada aos demais (Frisch 1941, PfeIfFer 1977, SмITH 1977, 1982, 1992). Esta rápida dispersão pelo grupo após o início é acelerada/otimizada através de transmissão visual (Verhejen 1956, Smith 1992).

A RA é o produto de dois fatores fundamentais: presença de CSA + SA no emissor e capacidade de resposta do receptor. A ausência de quaisquer destes fatores inviabiliza a reação, mesmo que haja a transmissão visual. O conjunto de atitudes que caracteriza uma típica RA sugere um estado de estresse e/ou de pânico generalizado entre os indivíduos do cardume, normalmente seguido de fuga.

Embora a RA freqüentemente ocorra entre espécies não aparentadas (Sмith 1992, Mathis \& SMith 1993), é proporcionalmente mais intensa entre as filogeneticamente mais próximas (SCHUTz 1956, Pfeiffer 1962, 1963b, 1966, 1967, 1977, 1982, Smith 1977, 1982, 1986, 1992, Chivers \& SMith 1998, Brown et al. 2000, 2003), sugerindo que seu estudo possa acrescentar subsídios à compreensão da afinidade entre espécies e grupos. Além de ser uma reação espécie-específica, Heczko \& SEghers (1981) demonstraram que a RA pode possuir também especificidade contextual, ou seja, uma mesma espécie pode apresentar reações distintas a situações distintas (e.g. diferentes predadores). Seus resultados corroboraram as sugestões de Smith (1977) e HoAre et al. (2004) no sentido de as RA constituírem-se em possíveis adaptações das espécies a seus habitats e principais predadores.

Os estudos sobre as reações de alarme dos Ostariophysi ganharam grande importância sistemática após PFEIFFer (1967) identificar a presença das CSA como autapomorfia para um gru- 
po monofilético que incluiria Gonorynchiformes e Ostariophysi. Estes táxons, embora não formalmente unificados à época, já eram considerados estreitamente relacionados desde GREENwOOD et al. (1966). Assim, a presença das CSA contribuiu nos estudos de Rosen \& GREENwood (1970) que levaram à unificação formal dos dois grupos sob um único táxon, Ostariophysi, superordem que passou a ser composta pelas séries Anotophysi (= Gonorynchiformes) + Otophysi (= "Ostariophysi" de antes). Esta estrutura geral foi corroborada (com reajustes) por FInK \& FINK (1981) e é hoje a composição mais amplamente aceita (LAUDER \& Liem 1983, Fink \& Fink 1996, Nelson 2006).

Há algumas considerações relevantes a serem feitas sobre a evolução deste sistema de alarme dentro de Ostariophysi devido às variações encontradas intra-grupo. Embora as CSA estejam quase sempre presentes em espécies que apresentam RA, podem ser encontradas em algumas espécies que não apresentam a reação, tais como o lambari cego das cavernas mexicanas - Astyanax Jordani (Hubbs \& Innes, 1936), Characidae - as piranhas e os pacus (ambos Characidae, Serrasalminae). Algumas explicações para a não ocorrência de RA mesmo na existência das CSA são sugeridas por SMITH (1977), como a baixa ocorrência de predadores em cavernas ou a voracidade predadora das piranhas. Ambos podem ser fatores causais na redução das pressões seletivas para a manutenção da RA, a qual é então reduzida e/ou perdida. Entretanto, aquele autor sugere que a queda no valor adaptativo da RA nestas espécies pode estar diretamente relacionada a seus hábitos especializados, uma vez que seu extrato de pele ainda pode induzir o alarme em outras espécies filogeneticamente próximas. Isto sugere que a ausência de RA esteja mais relacionada à perda da capacidade de percepção ou reação à substância do quê propriamente a sua produção.

A presença de CSA e a ocorrência de RA são considerados caracteres plesiomórficos para o táxon (Fink \& Fink 1981), de modo que se considera a ausência de RA em várias espécies de Ostariophysi como provável perda secundária. Pacus e piranhas são gêneros filogeneticamente próximos (Weitzman \& MaLAbarba 1998) e isto sugere que e a perda de sua RA possa ter ocorrido em um ancestral de hábitos especializados, o que exige estudos de ecologia histórica para uma melhor compreensão.

A origem adaptativa da SA ainda é controversa e tem sido discutida na forma de "alarm theories" e "non-alarm theories". As primeiras procuram reforçar os aspectos do benefício ao grupo, enquanto as segundas baseiam-se em outros aspectos adaptativos primários com funções diversas (que não especificamente a RA), tais como antiparasítica, antipatogênica ou em proteção a ferimentos (SMith 1982, 1986, 1992, BRown et al. 2003). A sugestão implícita nesta última é a de que a SA poderia constituir-se numa exaptação como causadora de RA, no sentido proposto por Gould \& VRBA (1982).

Há outros sistemas químicos de alarme em peixes que não a "Schreckreaktion", os quais vêm sendo descritos desde a década de 1970 (Smith 1992, Nordell 1998, Chivers et al. 2000, Mirza \& Chivers 2002, Mirza et al. 2003, entre outros). O primeiro estu- do detalhado da reação de alarme para um não-ostariofiso foi realizado por SмITH (1979) com Etheostoma exile (Girard, 1859) (Percidae), embora outros sistemas já houvessem sido citados anteriormente (ReEd 1969, G.J. CARMichael 1975, dados não publicados, apud Sмiтн 1982). Entretanto, o sistema de alarme do tipo "Schreckreaktion" permanece exclusivo dos Ostariophysi, o qual é conceitualmente definido pela liberação involuntária da "Schreckstoff" (SA) a partir das "Schreckstoffzellen" (CSA) (Pfeiffer 1967, Smith 1982, 1992). Some-se a isto o fato de a composição e a história evolutiva da substância de alarme neste táxon serem bastante peculiares (BRown et al. 2000, 2003).

A maior parte dos estudos sobre ecologia química (e particularmente os realizados sobre "Schreckreaktion") não incluem a ictiofauna neotropical, a qual permanece pouco conhecida quanto a este aspecto. Os estudos sobre RA realizados em ambiente natural são pouco comuns (Frisch 1938, Mathis \& Smith 1992, Wisenden et al. 1995, Irving \& Magurran 1997, Brown et al. 2000, Wisenden \& Thiel 2002) e com resultados às vezes polêmicos (Magurran et al. 1996, Wisenden et al. 2004).

Glandulocaudinae é uma subfamília de Characidae (Characiformes) que abrange cerca de 20 gêneros e 60 espécies distribuídas em sete tribos exclusivamente neotropicais (WeITZMAN et al. 1988, Weitzman \& Menezes 1998, CAstro et al. 2003), todos de pequeno porte (<15 cm sensu CASTRO 1999) e com comportamento natural de formar cardumes (NeLson 1964). Os membros desta subfamília apresentam tecido glandular na nadadeira caudal freqüentemente associado a escamas modificadas, especialmente na base do lobo superior dos machos nas espécies da tribo Glandulocaudini (Lophiobrycon + Glandulocauda + Mimagoniates, CASTro et al. 2003). Este conjunto de tecido glandular e escamas modificadas parece estar relacionado a várias formas de mecanismos de bombeamento de feromônios de acordo com a tribo que pertençam (Weitzman \& Menezes 1998). Apesar da carência de estudos sobre estas glândulas, presume-se que estejam ligadas à produção e distribuição de feromônios, e visem a atração ou o estímulo das fêmeas durante o acasalamento (Nelson 1964, Weitzman \& Fink 1985, Weitzman et al. 1988).

As duas espécies utilizadas neste trabalho, Mimagoniates lateralis (Nichols, 1913) e Mimagoniates microlepis (Steindachner, 1876), são pequenos lambaris da tribo Glandulocaudini que ocorrem em cardumes numerosos nos riachos de drenagem atlântica desde a costa leste à sul do Brasil (Weitzman et al. 1988, Menezes \& Weitzman 1990). As duas espécies foram escolhidas porque a presença das CSA e a ocorrência de RA nelas foi confirmada por Pfeiffer (1967), além de serem de pequeno porte e de captura fácil e freqüente em todas as estações do ano.

Mimagoniates lateralis é uma das menores espécies do gênero, com ocorrência endêmica e ameaçada de extinção (MACHADO et al. 2005). A espécie é encontrada freqüentemente em cardumes numerosos e preferencialmente à meia água ou um pouco mais à superfície, unicamente em pequenos alagados, poços ou regiões menos lóticas de pequenos corpos d'água. As águas onde é encontrada são sempre avermelhadas e ácidas,

Revista Brasileira de Zoologia 24 (4): 1163-1185, dezembro 2007 
abundantes em vegetação ribeirinha e aquática. A ocorrência da espécie é registrada apenas em uma estreita faixa de litoral entre a Serra do Mar e o oceano Atlântico, com cerca de 400 $\mathrm{km}$ de comprimento (Weitzman et al. 1988). Aí ocorrem sempre não muito distantes da vegetacão, para onde fogem quando assustados, utilizando-se da vantagem de a água ser escura. Devido a isto, e ao fato destes animais não serem muito ágeis, as coletas decorrem com relativa facilidade.

Mimagoniates microlepis possui a distribuição mais ampla do gênero, embora haja dúvidas quanto a seu status taxonômico, pois o táxon atual pode ser um complexo constituído por mais de uma espécie (Menezes \& Weitzman 1990). Esta espécie ocorre em cardumes numerosos nos riachos de águas claras e cristalinas da Mata Atlântica (Weitzman et al. 1988), sendo encontrados também nos trechos médio e alto da bacia do rio Iguaçu (INGENITO et al. 2004, АвіLноа 2005). Recentemente, sua ocorrência foi também citada para as cabeceiras do rio Tibagi (SANT'ANNA et al. 2006), bacia normalmente com águas mais barrentas e turvas que correm para oeste, mas principalmente em ecótopos não muito diferentes dos demais onde ocorre. Aí habitam região superficial na água e próximos às margens, preferencialmente em remansos ou ambientes menos lóticos dos riachos de águas limpas, onde a mata ripária é mais preservada mas não há vegetação ribeirinha. Ao contrário de M. lateralis, eles se mostram muito ágeis e de captura mais difícil. Os cardumes habitualmente realizam manobras de escape do tipo efeito fonte ("fountain effect" sensu Magurran \& Pitcher 1987) quando assustados na coleta, no qual fogem rapidamente para os lados e para o fundo e remontam novamente o cardume após alguns momentos. Este modo de fuga é coerente com o ambiente amplo e de águas claras, onde os riscos ficam bem visíveis.

Menezes \& Weitzman (1990) consideram que estas espécies sejam simpátricas e alotópicas. Entretanto, sua distribuição no litoral do estado do Paraná sugere serem espécies alotópicas e parapátricas por ocorrerem em habitats distintos, mas com contato de borda no ecótono. É comum encontrar-se ambas ocupando os mesmos corpos d'água, mas com freqüências de ocorrência inversamente proporcionais na drenagem, de modo que a abundância de $M$. microlepis aumenta de jusante para montante e a de $M$. lateralis aumenta de montante para jusante. Há um pequeno trecho de região ecotonal em cada rio onde as duas espécies podem ser encontradas em sintopia, como já observado por Schultz (1959). A ocorrência de ambas as espécies em absoluta sintopia vem sendo registrada nos riachos de águas escuras e ácidas da ilha costeira de São Francisco, um pouco mais ao sul da área aqui trabalhada.

A quimiorrecepção dos peixes pode sofrer grandes efeitos da exposição à águas poluídas (LemLY \& SMITH 1986) ou acidificadas (Lemly \& SMith 1987, Smith \& Lawrence 1988, Brown et al. 2000), o que pode influenciar diretamente a eficiência das reações de alarme. Verhejen (1956) foi um dos primeiros a sugerir a aplicação dos estudos das RA em análises ambientais, sobretudo quanto a poluentes. Burks \& LODGE (2002) apresen- tam uma pequena revisão sobre ecologia química em água doce. Estudos desta natureza vêm sendo realizados até agora por poucos autores (ChIVERs et al. 1999), os quais relatam um decréscimo na intensidade da RA diretamente proporcional à queda do $\mathrm{pH}$. Este fato pode ter relação com possíveis injúrias sofridas pelo epitélio olfativo em exposição crônica à acidez (LemLY \& Smith 1985, 1986, 1987, Smith \& Lawrence 1988). Também pode estar relacionado à desagregação estrutural da SA por uma provável protonação do grupo funcional [NO] do 3(N)-Óxido de hipoxantina (BRown et al. 2000).

Este estudo procura associar metodologia de mensuração do comportamento dos peixes em cardumes com estatística e análises gráficas, na tentativa de interpretar o comportamento dos peixes de uma maneira mais objetiva e eficiente. A expectativa é que se possa produzir dados adequados à utilização em estudos de ecologia, etologia, aquariofilia ou mesmo evolução e sistemática. Assim, é proposta a interpretação bimodal do comportamento a partir de bioensiaos realizados em aquário. Esta consiste na análise comportamental dos cardumes nos eixos horizontal e vertical, em situações de repouso (comportamento "natural") e alarme (após a indução da RA), a partir do quê são obtidos os valores matemáticos de posição para cada cardume analisado e de sua respectiva coesão (estado de agregação dos peixes). Os resultados fornecidos pela análise bimodal possibilitam a determinação da intensidade de reação (i) para cada espécie em valores objetivos e sistematizados.

O primeiro a interpretar a intensidade da "Schreckreaktion" foi Frisch (1941), quem propôs os sete níveis de intensidade freqüentemente utilizados desde então (SCHutz 1956, Pfeiffer 1962, 1963a, 1974). Entretanto, tais níveis são um tanto arbitrários, e por isso um novo método é apresentado no sentido de se obter uma análise mais minuciosa e objetiva, e também mais abrangente e realista. A intensidade de reação é aqui estimada através da síntese de três de seus componentes: período de reação $(\Omega)$, amplitude de reação $(\Lambda)$ e taxa média de compactação dos cardumes (TAC), que representa a coesão dos peixes dentro dos cardumes.

A intensidade da reação pode sofrer interações de variados fatores, desde os relativos à manutenção em aquário, aos ligados à variação biológica (PfeIfFer 1962). No sentido de se tentar minimizar a possibilidade de influências variáveis, todos os experimentos foram executados com condições de manutenção e experimentação equalizadas. Espera-se assim extrair dados concretos dos peixes estudados, em que as diferenças observadas sejam intrínsecas aos grupos utilizados ou às próprias espécies. Tais premissas amparam-se na literatura sobre "Schreckreaktion", a qual vem reafirmando a espécieespecificidade da RA desde o início dos estudos (FrISCH 1938, 1941, Schutz 1956, Pfeiffer 1963a, Smith 1986, 1992, Chivers \& SMith 1998, Brown et al. 2000, 2003).

A informação ecológica dos peixes neotropicais é ainda insuficiente para que se possa inferir possíveis influências do meio sobre a "Schreckreaktion". Isto torna fundamental a rea- 
lização de experimentos comparativos entre populações sintópicas de espécies diferentes, cujos exemplares provenham de uma mesma província (sensu MagurRan \& Pitcher 1987), bem como entre populações alotópicas de uma mesma espécie, cujos exemplares provenham de províncias distintas.

Os objetivos deste trabalho incluem: 1) aprimoramento de metodologia para o estudo objetivo e sistematizado do comportamento de cardumes em aquário; 2) determinação dos padrões de preferência dos peixes por posições nas direções horizontal e vertical, nas situações natural e em alarme; 3) determinação matemática da intensidade de reação (i) a partir dos componentes da reação de alarme ( $\Omega, \Lambda$ e TAC); 4) Análise comparativa das duas espécies de Mimagoniates quanto aos padrões estudados.

\section{MATERIAL E MÉTODOS}

\section{Obtenção dos peixes estudados}

Os indivíduos foram coletados em riachos do litoral do estado do Paraná (Fig. 1), área pertencente à Ecorregião Costeira Sudeste, da Região Hidrográfica do Atlântico Sul (Brasil 2006). As coletas foram realizadas sob autorização Ibama/PR 045/99 e processo 1193/98, com exemplares testemunho depositados na Coleção Ictiológica do Museu de História Natural Capão da Imbuia (MHNCI), da Prefeitura Municipal de Curitiba.

As coletas de $M$. lateralis ocorreram na parte alta do rio Perequê onde ainda é um ribeirão (Fig. $1 \mathrm{~A}$ ), e em alguns pequenos riachos afluentes. Todos estes pontos estão localizados nas proximidades da estrada do Lixão no município de Pontal do Paraná, e não muito distantes do mar. A região pertence à drenagem da sub-bacia da baía de Paranaguá e constitui-se em um complexo de confluências de ribeirões e riachos de restinga com profundidade média variando entre 0,5 a $1 \mathrm{~m}$, aproximadamente. Tais riachos possuem águas lênticas, vermelhas e bastante ácidas $(\mathrm{pH} \cong 3,0-4,5)$ devido aos ácidos húmicos, pouco oxigenadas (saturação de $\mathrm{OD} \cong 39 \%$ ) e com grande quantidade de sedimento orgânico em decomposição. Estes cursos d'água estão em sua maioria impactados (AвILHoA \& Duboc 2004) e com a mata ripária quase inexistente, embora possuam grande quantidade de vegetação ribeirinha. Tais riachos estão sujeitos a conexões na época das chuvas (janeiro a março) e constituem-se em ambientes exclusivamente dulcícolas, sem influência sazonal das marés. Foi observada a ocorrência de sambaquis nas redondezas, sendo possível que as águas da região possuam alto teor de cálcio. A temperatura da região é alta no verão e amena no inverno. Desta forma, como os ambientes de captura são lênticos, as águas nunca são muito frias, raramente ficando abaixo de $20^{\circ} \mathrm{C}$.

As coletas de $M$. microlepis foram realizadas basicamente no rio Cacatu (Fig. 1 A) e no ribeirão Dois de Fevereiro (Fig. 1 B), ambos na localidade de Cacatu, município de Antonina. Estes pontos de coleta pertencem à drenagem da sub-bacia da baía de Antonina, estando localizados na planície litorânea e não muito

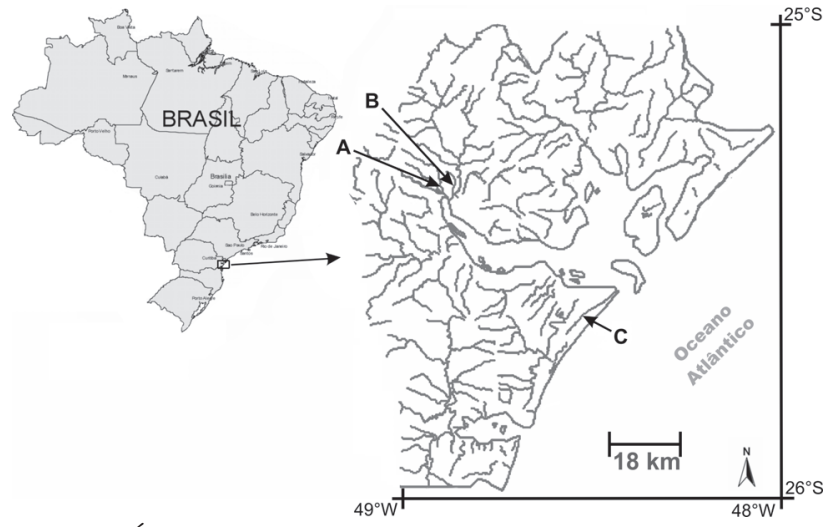

Figura 1. Áreas de coleta dos exemplares estudados no litoral do estado do Paraná. Mimagoniates microlepis em A) rio Cacatu e B) rio Dois de Fevereiro, município de Antonina; Mimagoniates lateralis em C) rio Perequê (município de Pontal do Paraná).

distantes do fundo da baía. Seu ambiente é caracterizado por cursos d'água que nascem na Serra dos Órgãos (região mais alta da Serra do Mar paranaense), com profundidade variando de 0,5 a 1,5 m nos locais de coleta. Estes cursos d'água possuem pouca vegetação ribeirinha (mais na época das cheias) e uma vegetação ripária mais ou menos bem conservada. Em geral, suas margens são barrancos ou rochedos, e não estão sujeitos a interações uns com os outros na época das chuvas. O ambiente é lótico, com águas normalmente claras, cristalinas, muito oxigenadas (saturação de $\mathrm{OD} \cong 95 \%$ ) e salinidade zero, sendo o $\mathrm{pH}$ mais próximo do neutro ( $\mathrm{pH} \cong 5,5-6,5)$. A temperatura da região é alta no verão e amena no inverno. Como o ambiente é lótico e estes rios nascem no alto da Serra do Mar, freqüentemente a temperatura da água fica abaixo de $16^{\circ} \mathrm{C}$ no inverno (com águas bem mais frias que as do Perequê).

Todas as coletas foram realizadas com puçás e peneiras, métodos que causam o mínimo de injúrias nos peixes. Após coletados, os peixes foram transportados ao laboratório de aquários do Departamento de Zoologia da Universidade Federal do Paraná, e lá mantidos em aquários-estoque separados por espécie. Estes aquários serviram para condicionar os animais ao ambiente do laboratório, bem como para aclimatá-los.

\section{Manutenção}

Não foi viável manter a água do ambiente natural de ocorrência de $M$. lateralis em aquário, já que o fato de ser rica em matéria orgânica, pobre em OD e muito ácida, faz com que logo se decomponha (cerca de $48 \mathrm{~h}$ ) e leve os animais à morte. Além disso, a tomada de imagens seria prejudicada por ser muito escura. Assim, optou-se pela utilização da água altamente transparente e pobre em matéria orgânica dos riachos da Serra do Mar, ambiente natural de M. microlepis. A estocagem dos peixes foi realizada em quatro aquários de vidro com 451 (50 x 30 x $30 \mathrm{~cm}$ ) e volume útil em torno de 40 1, com aerador perma- 
nentemente ligado. A temperatura da água foi mantida em $24^{\circ} \mathrm{C}$ \pm 1 . O fotoperíodo foi mantido natural do local através de lâmpadas controladas por células fotoelétricas ligadas ao ambiente externo.

Todos os bioensaios foram realizados no aquário experimental (Fig. 2), um aquário com capacidade aproximada de 45 $1(55 \times 27 \times 30 \mathrm{~cm})$ e isolado do meio externo para estímulos visuais, mas mantido da mesma forma e no mesmo local que os aquários-estoque. A única possibilidade de observação dos peixes neste aquário era através da câmera, sempre postada na posição da abertura frontal adequada.

Aspecto fundamental para as análises foi a gravação de um quadriculado $8 \times 8$ no vidro de trás para observação com câmera (Fig. 2, detalhe), cada quadro com dimensões de 60 x 45 $\mathrm{mm}$, num aprimoramento à metodologia utilizada por WALDMAN (1982). Este modelo difere daquele proposto por RADAKOV (1973), com a interpretação sendo aqui realizada na forma de setores de um plano cartesiano com oito faixas verticais (x1 a x8) e oito horizontais (y1 a y8). Foram arbitrados valores específicos de " $\mathrm{x}$ " e " $\mathrm{y}$ " para cada quadro e posição, com as posições de cada cardume sendo estimadas pela ponderação dos valores médios das posições horizontais e verticais de cada indivíduo. Estes valores são obtidos da leitura das respectivas posições horizontal e vertical de cada peixe no quadro onde se encontra em dado momento. A posição cartesiana neutra $(0,0)$ é determinada pelo cruzamento das linhas centrais horizontal e vertical, sendo a posição (x1, y1) arbitrada no quadro superior esquerdo e as demais em seqüência a esta (Fig. 2). Cada quadro possui um determinado fator de ponderação, com os conjuntos de valores dos fatores de deslocamento para cada coordenada sendo arbitrados da seguinte maneira (Fig. 2 detalhe): a) Posição horizontal - cada quadro variando nas posições horizontais $\mathrm{x} 1$ a x8 representa um fator de deslocamento horizontal " $\Delta \mathrm{x}$ ". Aos oito quadros foram arbitrados respectivamente os valores $-4,-3,-2,-1,1,2,3$ e 4 . b) Posição vertical - cada quadro variando nas posições verticais y1 a y8 representa um fator de deslocamento vertical " $\Delta y$ ". Aos oito quadros foram arbitrados respectivamente os valores 4,3 , 2, 1, -1, -2, -3 e -4.

\section{Protocolo experimental}

Os bioensaios consistiram em separar e aclimatar grupos de dez indivíduos oriundos dos aquários-estoque ao aquário experimental, onde eram mantidos e alimentados em posições e horários aleatórios por um período de seis dias. No sétimo dia era realizado o bioensaio, sempre pela manhã. Como o número de dez peixes nos cardumes nunca variou, este pode ser considerado o próprio tamanho eletivo de grupo - EGS ("elective group size" sensu Pitcher \& Parrish 1993).

Nesta etapa procurou-se eleger os maiores indivíduos, próximos ao tamanho máximo da espécie (supostamente adultos), pois segundo Schutz (1956) e PFeIFFer (1962) os jovens não efetuam ainda uma típica RA. WALdman (1982) e Sмith (1986) afirmam ainda que indivíduos jovens são incapazes de apresentar RA até pelo menos dois meses de idade.
A SA utilizada nos bioensaios foi sempre obtida da pele de um único indivíduo por sessão experimental, segundo método adaptado de Frisch (1938). A cada bioensiao um indivíduo era retirado de um dos aquários-estoque, medido e então devidamente desnervado através de seção medular ânterodorsal. Em seguida a pele dos dois lados do corpo era completamente extraída e imediatamente pesada, colocada em gral contendo uma pequena quantidade de água do aquário experimental (necessária apenas para amolecer a pele e permitir a drenagem do macerado), onde era picotada várias vezes com tesoura de ponta fina, e então macerada com um almofariz. A solução assim obtida era filtrada (para eliminar escamas e pedaços de pele) e diluída para uma concentração aproximada de $1 \mathrm{~g} / \mathrm{ml}$. A reação de alarme era induzida pela introdução de $50 \mathrm{ml}$ desta solução no aquário experimental através de sifonação por uma cânula plástica postada no canto anterior direito do quadro (quadro $\mathrm{x} 8, \mathrm{y} 1$ ), como pode ser observado na figura 2. A solução controle era a água do próprio aquário experimental, retirada minutos antes de cada teste e mantida à mesma temperatura.

Todos os registros foram obtidos através de câmera fotográfica, os quais foram divididos em dois conjuntos de baterias: controle (Ctrl) e bioensaio experimental, cada qual com quatro repetições. Ambas as baterias possuíam 40 fotogramas cada e eram sempre realizadas seqüencialmente na ordem [controle $\rightarrow$ bioensaio] sempre na manhã do sétimo dia e após a introdução dos peixes no aquário experimental (quando já estavam aclimatados). Todas as fotos da bateria do Ctrl foram tomadas a $1 / \mathrm{min}$. A bateria do bioensaio foi obtida de forma segmentada: repouso ou fase neutra $-\mathrm{FN} \rightarrow 10$ fotos tomadas $1 /$ min.; fase água - FA $\rightarrow 10$ fotos tomadas $1 /$ min.; fase susto (o alarme) - FS $\rightarrow 20$ fotos, com as primeiras dez tomadas $1 / 30$ s e as dez seguintes tomadas $1 / \mathrm{min}$. A FA era iniciada pela introdução da solução controle logo após a tomada da foto 10 (final da FN). Note-se que após a tomada da foto 20 (final da FA) foi efetuado um hiato temporal de uma hora antes de dar seqüência às fotos da FS, pois os peixes ficavam um pouco mais agitados após a introdução da água e alcançavam uma nova estabilização comportamental neste período. Ao final das seções o filme era revelado e os negativos ordenados, numerados, emoldurados e projetados em telão, como "dianegativos", para a obtenção dos dados de posição dos peixes.

Todos os dados de posição para as análises estatísticas foram obtidos apenas a partir dos registros fotográficos, onde o número de indivíduos foi determinado separadamente nos eixos X e Y para cada dianegativo (fotograma). Entretanto, a realização de filmagens eventuais dos bioensaios experimentais auxiliou sobremaneira na compreensão global do comportamento de alarme destas espécies.

\section{Análise de dados}

As posições dos cardumes em cada fotograma foram determinadas através da estimativa de seus respectivos centros geométricos. Estes são aqui obtidos pelo cruzamento dos resul- 


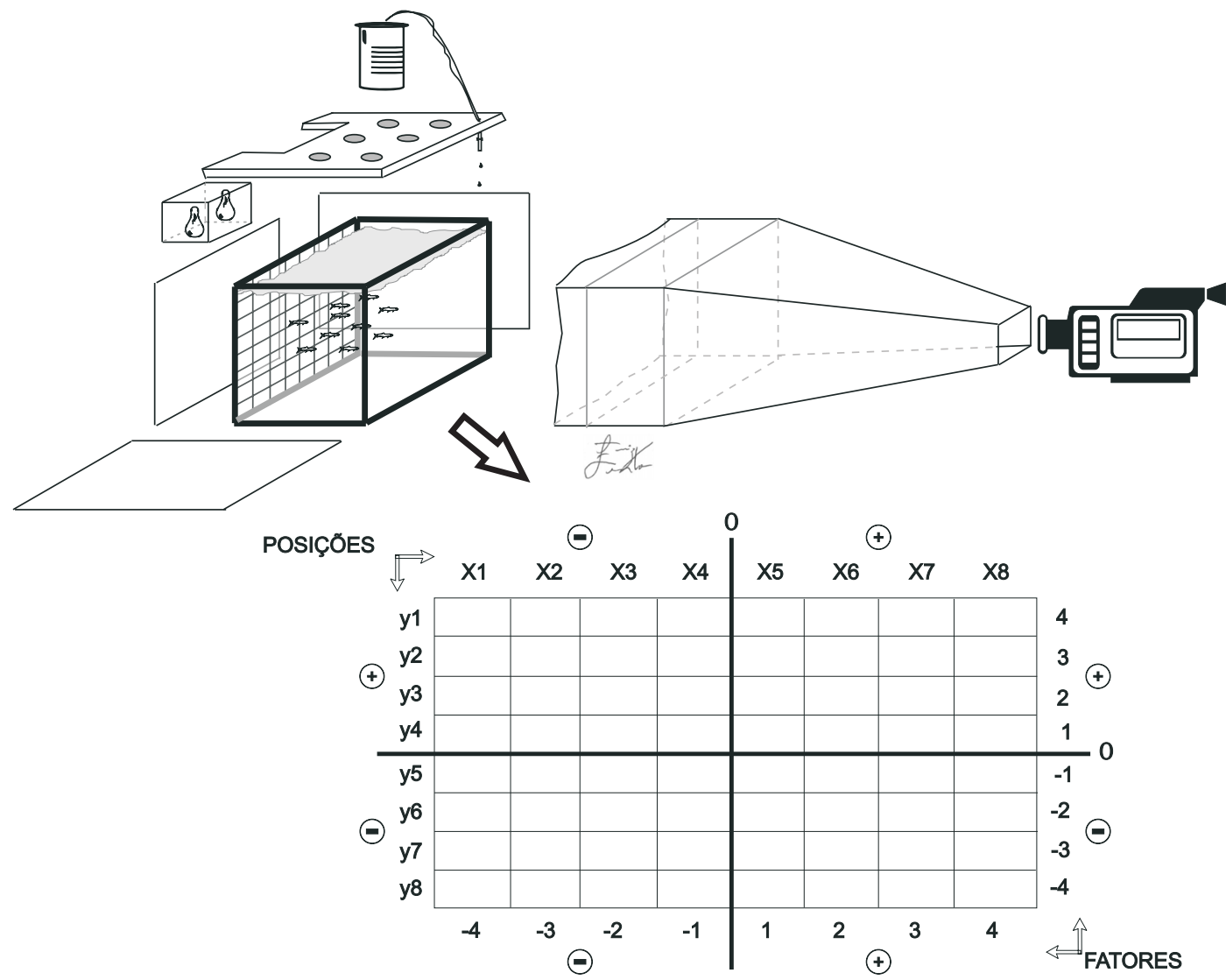

Figura 2. Aquário experimental, com a grade de fundo em detalhe, demonstrando cada uma das oito posições horizontais ( $\mathrm{x}$ ) e verticais (y), com seus respectivos fatores de posição.

tados das informações horizontal e vertical, com cada uma das posições sendo projetada na grade do aquário experimental e interpretada como pontos em um plano cartesiano (x, y). Assim, cada ponto é considerado como a posição média bidimensional do cardume em um determinado momento, e é obtido pela ponderação dos respectivos fatores de posição " $\Delta$ " com as informações horizontal e vertical por cardume e em cada fotograma, como será descrito a seguir.

WaLDMAN (1982) utilizou um modelo matemático simplificado com nove quadros para a interpretação da posição momentânea de cada cardume, o qual foi aqui aperfeiçoado e adaptado para um modelo com 64 quadros. Os cálculos a seguir consideram apenas os valores discretos e servem para determinar as posições médias horizontais e verticais de cada cardume em cada um dos fotogramas:

Posição média horizontal do cardume: $X=\Sigma \Delta(\Sigma x n) \rightarrow X$ $=-4(\Sigma x 1)-3(\Sigma x 2)-2(\Sigma x 3)-(\Sigma x 4)+(\Sigma x 5)+2(\Sigma x 6)+3(\Sigma x 7)+$ $4\left(\sum x 8\right)$, onde: $X=$ posição horizontal média do cardume num dado momento (fotograma), $\Sigma x n=$ somatório do número de indivíduos na posição cartesiana horizontal "xn"; $\Delta=$ fator de posição relativo a "xn", o qual varia de $-4 \mathrm{a}+4$ (Fig. 2).
Posição média vertical do cardume: $\mathrm{Y}=\Sigma \Delta(\Sigma \mathrm{yn}) \rightarrow \mathrm{Y}=$ $4(\Sigma y 1)+3(\Sigma y 2)+2(\Sigma y 3)+(\Sigma y 4)-(\Sigma y 5)-2(\Sigma y 6)-3(\Sigma y 7)-$ 4( y8), onde: $\mathrm{Y}=$ posição vertical média do cardume num dado momento (fotograma); $\Sigma$ yn = somatório do número de indivíduos na posição cartesiana vertical "yn"; $\Delta$ = fator de posição relativo a "yn", o qual varia de +4 a -4 (Fig. 2).

Os fatores de posição relativos a " $\mathrm{n}$ " são fundamentais na aplicação do modelo, já que possibilitam a síntese de todas as posições individuais de um cardume em um único ponto médio para um dado momento, e assim formam a base da interpretação do deslocamento nas direções horizontal e vertical a partir do centro. Para o modelo proposto (em qualquer caso), o âmbito da variação será \pm 4 (EGS), e considerando-se que neste trabalho o EGS foi sempre de 10 peixes, os valores de posição dos cardumes podem variar entre -40 e +40 em ambas as direções, horizontal ("X") e vertical ("Y").

A determinação dos fatores de posição foi realizada de modo que os valores sejam maiores nos extremos e menores no centro, mas sem anular estes últimos (ao contrário de WALDMAN 1982). Isto decorre do fato de os valores serem arbitrários e partirem do pressuposto teórico da distribuição central 
dos peixes em situação normal no aquário. Assim, espera-se que a RA induza o aumento dos valores modulares de posição proporcionalmente à distância do centro, que é a região teoricamente nula. Os valores em módulo determinam a quantidade de deslocamento a partir do centro e assim os sinais indicam o sentido do deslocamento, o qual deve ser assim interpretado: Horizontal - centro $\rightarrow$ esquerda $\Rightarrow-$ (deslocamento negativo) ou centro $\rightarrow$ direita $\Rightarrow+$ (deslocamento positivo). Vertical: centro $\rightarrow$ superfície $\Rightarrow+$ (deslocamento positivo) ou centro $\rightarrow$ fundo $\Rightarrow-$ (deslocamento negativo).

A variação na agregação (ou coesão) dos peixes dentro dos cardumes também pode ser interpretada a partir dos dados assim obtidos, sendo que sua determinação está totalmente baseada na contagem do número total de quadros ocupados pelo EGS em cada fotograma. A coesão é interpretada em função da variação do espaço ocupado pelo EGS (cardumes), no sentido proposto por MagurRan \& Pitcher (1987), e foi aqui realizada para todo o conjunto de registros.

Cada quadro é capaz de conter todo o EGS, bem como pode ser ocupado por apenas um indivíduo em algum fotograma, de modo que o número mínimo possível de quadros ocupados por foto é 1 e o máximo o próprio EGS (=10, neste caso). Com base nestes prepostos a agregação pode ser representada por um índice de dispersão absoluto, o índice de dispersão no cardume - IDC, o qual representa diretamente o número total de quadros ocupados pelo EGS em um fotograma. O âmbito do IDC varia (em valores discretos) de 1 quando a dispersão é mínima (agregação máxima), a 10 quando a dispersão é máxima (agregação mínima).

A interpretação da agregação torna-se facilitada quando apresentada em uma escala constante. Desta forma, padronizou-se sua variação numa escala de 0 a 1 através de uma adaptação do método utilizado por HurLbert (1978) na padronização da medida de Levins para amplitude de nicho (KREBs 1998). O novo índice foi denominado taxa de agregação no cardume - TAC, o qual é obtido a partir da padronização de IDC (1 $\longrightarrow \rightarrow$ $10)$ e expresso em percentual: $0 \longrightarrow 100 \%$. A fórmula para sua obtenção é a seguinte:

$$
T A C=1-\left(\frac{I D C-Q_{\min }}{E G S-Q_{\min }}\right) \times 100
$$

onde: TAC = taxa de agregação no cardume, em porcentagem, IDC = índice de dispersão no cardume (número de quadros ocupados no fotograma), EGS = número de indivíduos no cardume, $\mathrm{Q}_{\min }=$ mínimo número possível de quadros ocupados por fotograma.

Os dados foram analisados comparativamente através de estatística não-paramétrica pela utilização de testes de ' $U$ ' de Mann-Whitney para amostras independentes (SIEGEL 1975), sempre com nível de significância de $5 \%(\alpha=0,05)$.

A análise de dados longitudinais realiza estimativas baseadas nos comportamentos das curvas obtidas dos dados (JONES 1993), diminuindo assim a natural perda de informações decor- rente do uso de médias e ainda possibilitando a interpretação gráfica dos resultados. Este tipo de análise envolve um conjunto de unidades de investigação classificadas em diferentes subgrupos, segundo um ou mais tratamentos ao longo de unidades de observação seriadas. Entre seus principais objetivos está encontrar um modelo que represente adequadamente o conjunto de dados, dentre os inúmeros possíveis. Um procedimento para a seleção do modelo adequado é a aplicação do teste assintótico da razão de verossimilhança. Este compara dois modelos em que um é uma forma restrita do outro, e verifica se a adição de parâmetros melhora ou não o ajuste da curva. Outro procedimento é a utilização do critério de informação Akaike (AIC), onde o modelo que apresentar o menor AIC é o escolhido (JoNEs 1993).

Neste estudo os peixes foram determinados como sendo as unidades de investigação, com as fases sendo os tratamentos e os fotogramas (= dianegativos) as unidades de observação. Para tanto, foi necessário realizar-se a avaliação $a$ priori de três importantes aspectos: 1) número e balanceamento das condições de avaliação, 2) presença de observações incompletas, e 3) processo de amostragem e natureza dos dados.

O protocolo experimental aqui proposto (Fig. 3) determina quatro repetições, cada uma dividida em três tratamentos: A) 50 fotos da situação de repouso em cada repetição (40 de Ctrl + 10 da FN), totalizando 200 registros, B) 10 fotos da FA em cada repetição, totalizando 40 registros, e C) 20 fotos da FS em cada repetição, totalizando 80 registros. O grande desbalanceamento observado na distribuição dos dados pelos tratamentos $(200-40$ - 80) indicou que o modelo de efeitos aleatórios fosse considerado o mais adequado. Isto se deve ao grande número de parâmetros necessários para descrever a estrutura de covariância, no que se optou pela utilização do modelo linear misto de Laird-Ware (LAIRD \& WARE 1982).

O modelo de Laird-Ware utiliza procedimentos interativos de estimação e testes de hipóteses baseados no método de máxima verossimilhança, sendo que cada unidade tem o seu próprio modelo. Isto possibilita que diferentes unidades possam ter diferentes números de observações, bem como diferentes tempos de observação (LaIRD \& WARE 1982). Modelos deste tipo possuem dois estágios baseados na identificação de características individuais e populacionais. Em situações cujo objetivo é o ajuste de curvas, os modelos de efeitos aleatórios assumem a existência de curvas sub-populacionais fixadas, em torno das quais existem variações aleatórias das curvas individuais. Também ocorrem variações aleatórias de medidas em torno dessas curvas individuais, sendo estas medidas independentes dos efeitos aleatórios individuais (SINGER \& ANDRAde 1986).

A estimação dos parâmetros e seus respectivos AIC's foram gerados pelo programa Fortran Car1, no Laboratório de Estatística (PET), Universidade Federal do Paraná. Os resultados foram apresentados como equações de ajuste para os deslocamentos nos eixos horizontal $(\Delta \mathrm{X})$ e vertical $(\Delta \mathrm{Y})$ em função dos fotogramas seqüenciais (t). 


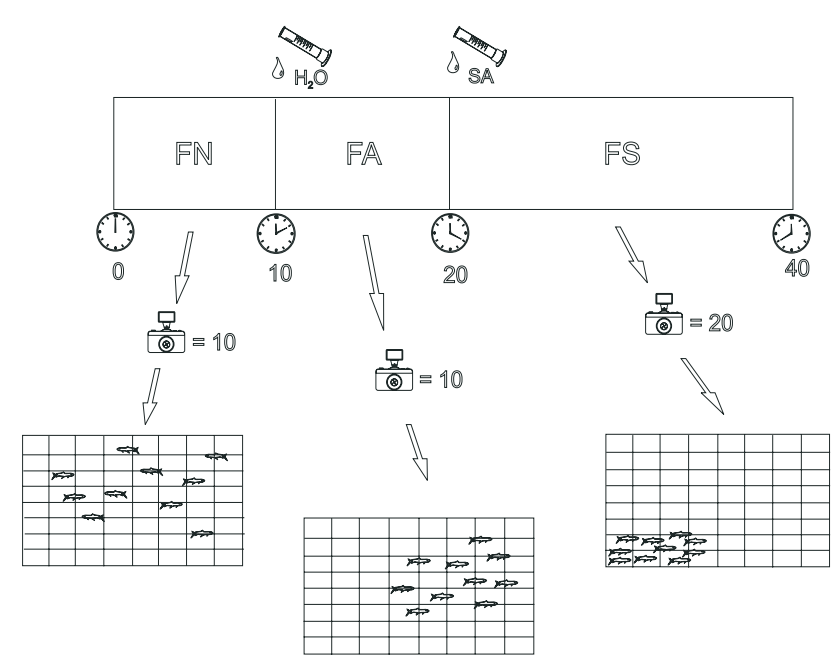

Figura 3. Desenho experimental demonstrando a distribuição de tempo (40 min.) e fotogramas (40 fotos) nas três baterias de análises: (FN) fase neutra, (FA) fase água, (FS) fase susto, $\left(\mathrm{H}_{2} \mathrm{O}\right)$ água utilizada como controle, introduzida ao final da FN, (SA) substância de alarme, introduzida ao final da FA. A figura ilustra ainda uma síntese geral dos resultados obtidos para o comportamento dos peixes.

\section{Intensidade de reação - proposta de análise}

A proposta aqui apresentada para a determinação da intensidade de reação parte do pressuposto que a reação de alarme esteja diretamente relacionada a pelo menos três fatores: 1) o tempo em que os peixes permanecem "assustados", 2) a abrangência da fuga e 3) a reação do grupo, os dois últimos interpretados em função da coesão entre os peixes dentro dos cardumes (TAC). Desta forma, uma vez que estes fatores estejam relacionados, sua análise conjuntural pode fornecer valores numéricos mensuráveis e passíveis de serem interpretados como "intensidade da reação". Isto vem implementar objetividade e robustez na compreensão das diferenças entre as espécies nos aspectos estudados.

Quando interpretado graficamente através da análise de dados longitudinais, o deslocamento dos peixes no tempo pode freqüentemente ser representado por uma parábola, a qual é regida por uma equação do segundo grau do tipo $y=a x^{2}+b x+c$ (Fig. 10). Isto permite dissecá-lo na forma de dois componentes principais:

$(\Omega)$ período de reação - o espaço de tempo efetivo da reação (momentos, neste caso), medido desde a posição inicial (momento inicial) até seu retorno à mesma posição. Interpretado como uma estimativa média do conjunto de dados estudados, cujo significado é a duração do susto. É representado graficamente pelo comprimento da parábola no eixo X.

$(\Lambda)$ amplitude de reação - a variação espacial total utilizada durante a reação, medida desde o momento na posição inicial da reação até o momento de seu retorno à mesma posi- ção. Interpretada como uma estimativa média do conjunto de dados estudados, onde o ponto crítico do deslocamento é obtido no vértice da parábola e significa a abrangência da fuga. É representada graficamente pela altura da parábola no eixo Y.

A posição inicial (o respectivo "Y") - conceitualmente igual à posição final - é obtida pela aplicação do momento inicial na equação $(x=t=1)$. Substituindo-se a posição obtida na equação do segundo grau e resolvendo-a pelo simples cálculo de suas raízes para $\mathrm{Y}=0$ (equação de Bháskara $x=-b \pm \sqrt{b^{2}-4 a c} / 2 a$ ), obtém-se o momento final como uma das raízes (a outra é o próprio momento inicial). O momento " $\mathrm{t}$ " do vértice da parábola também pode ser obtido a partir da equação do segundo grau, através da resolução direta da expressão $x=-b / 2 a$. Uma vez obtido o " $\mathrm{x}$ ", a posição $(\mathrm{x}, \mathrm{y})$ do vértice é determinada através da extração do valor relativo de "y" da equação inicial pela aplicação do valor encontrado para " $\mathrm{x}$ ".

Uma vez que o comportamento de deslocamento no tempo possa ser expresso em função de uma parábola, a relação entre os componentes $\Omega$ e $\Lambda$ pode ser estimada graficamente como a área da parábola delimitada pela reta que corta as posições inicial e final, denominada de espaço gráfico de reação EGR (Fig. 10). Sua obtenção pode ser realizada a partir do cálculo integral ou de forma aproximada e muito mais simples pelo método da exaustão de Arquimedes, onde a área da parábola é determinada pelo produto de $2 / 3$ da base pela altura, notação expressada aqui como EGR $=2 \Omega \Delta / 3$.

O espaço de reação é apenas uma das feições da "intensidade de reação", pois está baseado em apenas dois fatores (espaço e tempo), e sua análise pode ser substancialmente implementada pela inserção do fator "social" TAC. Assim, sua interpretação passa a ser tridimensional e mais robusta, vindo somar dados no conjunto e auxiliando a amplificação das possíveis diferenças.

Propõe-se que a intensidade de reação (i) seja obtida através da multiplicação do fator espaço-temporal EGR pelo fator social TAC, como demonstrado na notação i = EGR x TAC $\rightarrow$ $\mathrm{i}=(2 \Omega \Delta / 3) \times \mathrm{xTAC}$.

\section{RESULTADOS}

As duas espécies formaram cardumes polarizados e sincronizados (Fig. 4), e demonstraram notáveis diferenças de estado, movimentação e preferências por posição no aquário, perceptíveis mesmo através das observações diretas. Os resultados das análises corroboraram as observações realizadas, e as estimativas sugerem distinção entre as espécies quanto às preferências por posição e deslocamento. Conseqüentemente, as respostas às introduções do controle (água) e da substância de alarme também se mostraram distintas.

As duas espécies demonstraram comportamentos significativamente distintos, embora tais diferenças não tenham sido estimadas para as comparações intraespecíficas dos comportamentos observados entre os grupos controle (Ctrl = 40 fotogra- 


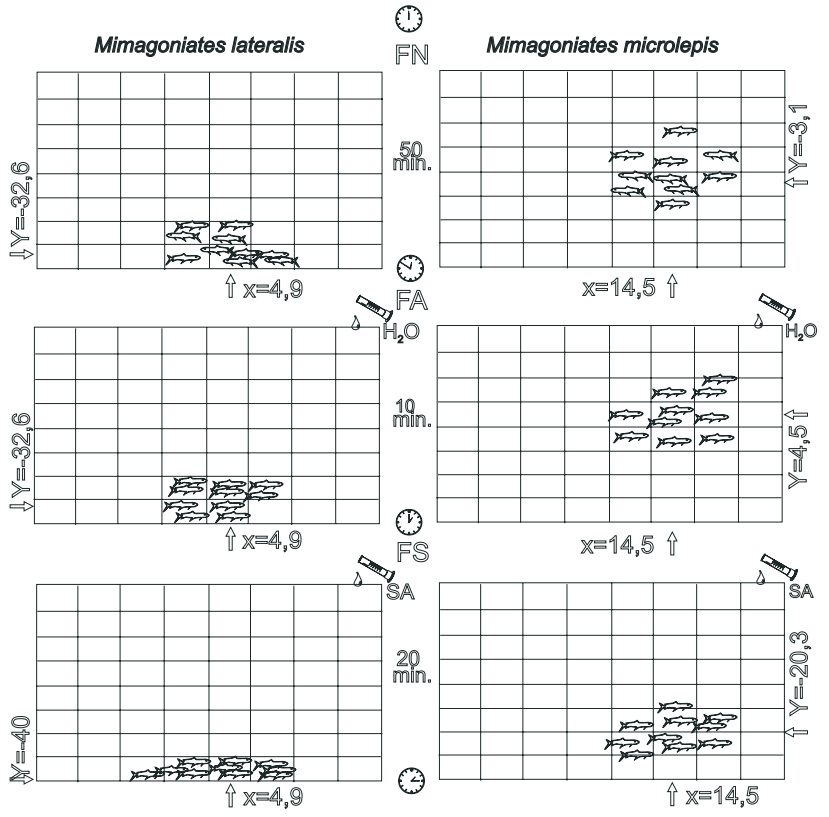

Figura 4. Síntese dos resultados obtidos para o comportamento dos peixes para as duas baterias do experimento: (FN) fase neutra, aqui constituída de controle + FN, (FA) fase água, (FS) fase susto, $\left(\mathrm{H}_{2} \mathrm{O}\right)$ água utilizada como controle, introduzida ao final da FN, (SA) substância de alarme, introduzida ao final da FA. A ilustração demonstra os pontos médios preferenciais dos cardumes nas posições horizontal $(X)$ e vertical $(Y)$.

mas por repetição) e fase neutra ( $\mathrm{FN}=10$ fotogramas por repetição). Deste modo, todas as interpretações gráficas (através da análise de dados longitudinais) dos resultados dos grupos FN incluem os resultados dos grupos Ctrl nas análises de ambas as espécies.

A fusão dos dados de Ctrl com os de FN fornece um conjunto desbalanceado $(50+10+20$ fotogramas) e a análise utilizada é sensível ao desbalanceamento dos dados. Entretanto, o conjunto foi estimado homogêneo pela análise de dados longitudinais e isto possibilitou o descarte de 30 dos registros, tornando assim o conjunto mais balanceado $(20+10+20$, respectivamente). Os descartes não tiveram nenhuma influência nos resultados, mas aumentaram a eficiência destas análises, onde os modelos ajustaram estatisticamente polinômios do primeiro grau para as fases no eixo $\mathrm{X}$ e polinômios do segundo grau como modelos para as fases no eixo $\mathrm{Y}$, como será discutido nas próximas seções.

As estimativas para FN demonstraram a preferência dos indivíduos de $M$. lateralis pela região central e mais ao fundo do aquário experimental, permanecendo do meio para baixo na maior parte do tempo (Fig. 4). As observações diretas mostraram que os peixes tenderam a estar sempre proporcionalmente mais concentrados no centro quanto mais à superfície e mais espalhados quanto mais ao fundo. Já os indivíduos de $M$. microlepis estiveram sempre mais próximos ao centro e um pouco à direita do aquário na maior parte do tempo (Fig. 4).

O comportamento dos peixes em FA também se mostrou distinto entre as espécies, sendo que ambas ingressaram em estado de alerta após demonstrarem clara percepção à entrada de água no aquário nesta fase (Fig. 4). Entretanto, houve aqui uma marcada diferença comportamental para M. microlepis, cujos indivíduos demonstraram deslocamento no sentido da corrente d'água quando o controle (água) era introduzido através do tubo do alarme (Fig. 2). As observações diretas mostraram que tal comportamento foi sempre iniciado pela atitude investigativa (sensu Csany 1985) de um ou poucos indivíduos. As alterações no deslocamento foram captadas pelas análises estatísticas, como pode ser observado pelos resultados demonstrados nas tabelas I e II, sendo que a introdução do controle não influenciou a dispersão dos peixes ou a coesão dos cardumes (Tab. IV). O estado de perturbação dos peixes em FA diminuiu paulatinamente de intensidade até seu retorno à aparente normalidade num período aproximado de uma hora em todas as repetições. Isto foi também observado nos pré-ensaios, os quais foram utilizados na determinação desse período de pausa aplicado entre o término da FA e o início da FS, como descrito no desenvolvimento metodológico.

Tabela I. Testes de U de Mann-Whitney para as análises comparativas das posições horizontais no eixo $\mathrm{X}$, mostrando os valores estimados para $U$ e $Z$. $\left(^{*}\right)$ Significativo $(p<0,05)$, (ns) não significativo $(p \geqslant 0,05)$, ( $n$ ) amostras, (Ctrl) controle, (FN) fase neutra, (FA) fase água, (FS) fase susto.

\begin{tabular}{lrrcrr}
\hline \multicolumn{1}{c}{$\mathrm{U}$} & $\mathrm{Z}$ & $\mathrm{p}$ & $\mathrm{n}_{1}$ & $\mathrm{n}_{2}$ \\
\hline M. lateralis & & & & & \\
Ctrl x FN * & 2520,50 & $-2,027$ & 0,043 & 159 & 40 \\
Ctrl x FA ns & 2952,50 & 0,699 & 0,484 & 159 & 40 \\
Ctrl x FS * & 4031,00 & $-3,999$ & 0,000 & 159 & 75 \\
FN x FA * & 580,50 & 2,114 & 0,035 & 40 & 40 \\
FN x FS ns & 1206,00 & $-1,727$ & 0,084 & 40 & 75 \\
FA x FS * & 943,50 & $-3,269$ & 0,001 & 40 & 75 \\
M. microlepis & & & & & \\
Ctrl x FN ns & 2779,00 & 1,004 & 0,316 & 159 & 39 \\
Ctrl x FA ns & 2728,00 & $-1,390$ & 0,165 & 159 & 40 \\
Ctrl x FS * & 4538,50 & $-3,355$ & 0,001 & 159 & 78 \\
FN x FA * & 578,50 & $-1,978$ & 0,048 & 39 & 40 \\
FN x FS * & 948,50 & $-3,314$ & 0,001 & 39 & 78 \\
FA x FS ns & 1336,00 & $-1,276$ & 0,202 & 40 & 78 \\
M. lateralis x M. microlepis & & & & \\
Ctrl * & 4744,50 & $-9,637$ & 0,000 & 159 & 159 \\
FN * & 525,00 & $-2,502$ & 0,012 & 40 & 39 \\
FA * & 166,50 & $-6,100$ & 0,000 & 40 & 40 \\
FS * & 2380,00 & $-1,991$ & 0,046 & 75 & 78 \\
\hline
\end{tabular}


Tabela II. Testes de U de Mann-Whitney para as análises comparativas das posições verticais no eixo $Y$, mostrando os valores estimados para U e Z. $\left(^{*}\right)$ Significativo $(p<0,05)$, (ns) não significativos ( $p \geqslant 0,05),(n)$ amostras, (Ctrl) controle, (FN) fase neutra, (FA) fase água, (FS) fase susto.

\begin{tabular}{lccccc}
\hline & $\mathrm{U}$ & $\mathrm{Z}$ & $\mathrm{p}$ & $\mathrm{n}_{1}$ & $\mathrm{n}_{2}$ \\
\hline M. lateralis & & & & & \\
Ctrl x FN ns & 3127,50 & 0,162 & 0,871 & 159 & 40 \\
Ctrl x FA ns & 3086,00 & 0,291 & 0,771 & 159 & 40 \\
Ctrl x FS * & 3508,50 & 5,179 & 0,000 & 159 & 40 \\
FN x FA ns & 798,00 & $-0,019$ & 0,981 & 40 & 40 \\
FN x FS * & 829,00 & 4,054 & 0,000 & 40 & 75 \\
FA x FS * & 840,00 & 4,003 & 0,000 & 40 & 75 \\
M. microlepis & & & & & \\
Ctrl x FN * & 2258,50 & 2,627 & 0,009 & 159 & 39 \\
Ctrl x FA ns & 3017,00 & $-0,501$ & 0,616 & 159 & 40 \\
Ctrl x FS * & 2042,50 & 8,388 & 0,000 & 159 & 78 \\
FN x FA * & 541,50 & $-2,340$ & 0,019 & 39 & 40 \\
FN x FS * & 798,50 & 4,181 & 0,000 & 39 & 78 \\
FA x FS * & 253,50 & 7,433 & 0,000 & 40 & 78 \\
M. lateralisx M. microlepis & & & & \\
Ctrl * & 286,50 & $-15,089$ & 0,000 & 159 & 159 \\
FN * & 63,00 & $-7,041$ & 0,000 & 40 & 39 \\
FA * & 3,00 & $-7,676$ & 0,000 & 40 & 40 \\
FS * & 154,00 & $-10,198$ & 0,000 & 75 & 78 \\
\hline
\end{tabular}

Em FS, nos bioensaios de alarme propriamente ditos, os peixes de ambas as espécies demonstraram perceber a presença da SA logo que foi introduzida. Isto ocorreu através de uma intensa reação iniciada em menos de 10 s, com intensidade declinante após alguns minutos. Durante o período inicial da reação os peixes manifestaram uma clara tática de confusão, quando se agregaram mais e demonstraram um comportamento semelhante ao de um carrossel. Neste os indivíduos alternam movimentos rápidos e circulares com paradas bruscas e em tempos diferentes uns dos outros, formando uma turba onde os indivíduos demonstram sacudidas rápidas e aleatórias ("skittering" sensu MagurRan \& Pitcher 1987). O conjunto também se desloca rápida e aleatoriamente sem nenhuma preferência perceptível por posição (horizontal ou vertical). Após um período de tempo os peixes permaneceram mais agregados na região central e no fundo do aquário, procurando distanciar-se da região de introdução do alarme. Poder-se-ia interpretar este comportamento como uma tática de evasão ("evasion" sensu Pitcher \& Parrish 1993) seguida pela de se esconder ("hiding" sensu Magurran \& Pitcher 1987). Além disso, a coesão dos cardumes aumentou em ambas as espécies e os peixes ficaram muito mais ariscos a quaisquer perturbações (e.g. sons do ambiente externo), embora também exibissem movimentação menor.

\section{Análise do deslocamento horizontal}

As estimativas obtidas pela prova de ' $U$ ' de Mann-Whitney para as comparações posicionais horizontais intra e interespecíficas estão sintetizadas na tabela I, e a tabela III detalha os dados de posição horizontal estimados para os cardumes. A figura 5 ilustra estes resultados através da demonstração gráfica das posições médias (com seus respectivos desvios padrão) de ambas as espécies em cada fase.

Os resultados mostram que as espécies podem ser distinguidas quanto ao deslocamento e preferência por posição no eixo horizontal, com as comparações interepecíficas resultando em valores significativos para todas as fases com níveis de 'p' muito baixos (Tab. I). Apenas a fase susto (FS) sugere uma possível semelhança de comportamento entre as espécies, uma vez que o resultado é passível de ser interpretado como não significativo ( $n s)$ por arredondamento ( $\mathrm{p} \cong 0,046$ ).

Mimagoniates lateralis em situação natural ocupou uma posição horizontal média entre 0,2 e 8,7, o que é muito próximo do centro, enquanto M. microlepis situou-se entre 8,2 e 13,9, um pouco mais à direita (figuras 5 e 6 , tabela III, considerando-se os valores incluídos dentro do intervalo de confiança de $95 \%$ das fases Ctrl e FN). Levando-se em conta apenas as fases FA e FS, percebe-se uma maior movimentação dos cardumes, com respectiva ampliação dos limites de movimentação pelo aquário. Neste caso, as posições médias preferenciais de M. lateralis oscilaram entre $-3,7$ e 12,5 , e as de $M$. microlepis entre 12,6 e 18,1 (figuras 5 e 6 , tabela III, considerando-se os valores incluídos dentro do intervalo de confiança de $95 \%$ das fases FA e FS).

As análises estatísticas pelo teste de U estimaram que $M$. lateralis demonstrou semelhanças na posição horizontal apenas entre Ctrl e FA e entre FN e FS, com as demais posições sendo consideradas distintas (Tab. I). Importante observar um claro aumento do desvio padrão em FS (Fig. 5 e Tab. III), o que vem corroborar o observado aumento na agitação dos cardumes desta espécie, com sensível aumento na movimentação horizontal. M. microlepis demonstrou maior homogeneidade nas posições (Figs 5 e 6, Tab. III), com as médias observadas para Ctrl sendo estimadas semelhantes às de FN e FA (Tab. I). As fases FN e FA desta espécie foram estimadas serem significativamente distintas entre si (embora o $\mathrm{p} \cong 0,048$ tenha ficado muito próximo de "ns"), assim como FN e FS. Por outro lado, FA foi considerada semelhante à FS. De modo diferente ao que ocorreu com M. lateralis, não foi observada nenhuma alteração na agitação dos cardumes em FA ou FS através do aumento no desvio padrão, podendo mesmo ser observada uma leve queda nos valores (Fig. 5 e Tab. III).

A análise de dados longitudinais forneceu estimativas que não sugerem diferenças significativas de posição horizontal entre as diversas fases de uma mesma espécie, mas as estimaram como significativamente distintas entre as duas espécies (Fig. 6). Isto pode ser depreendido a partir das equações obtidas para os modelos de ajuste, com ambas as espécies apresentando retas distintas como resultado. A reta estimada como 

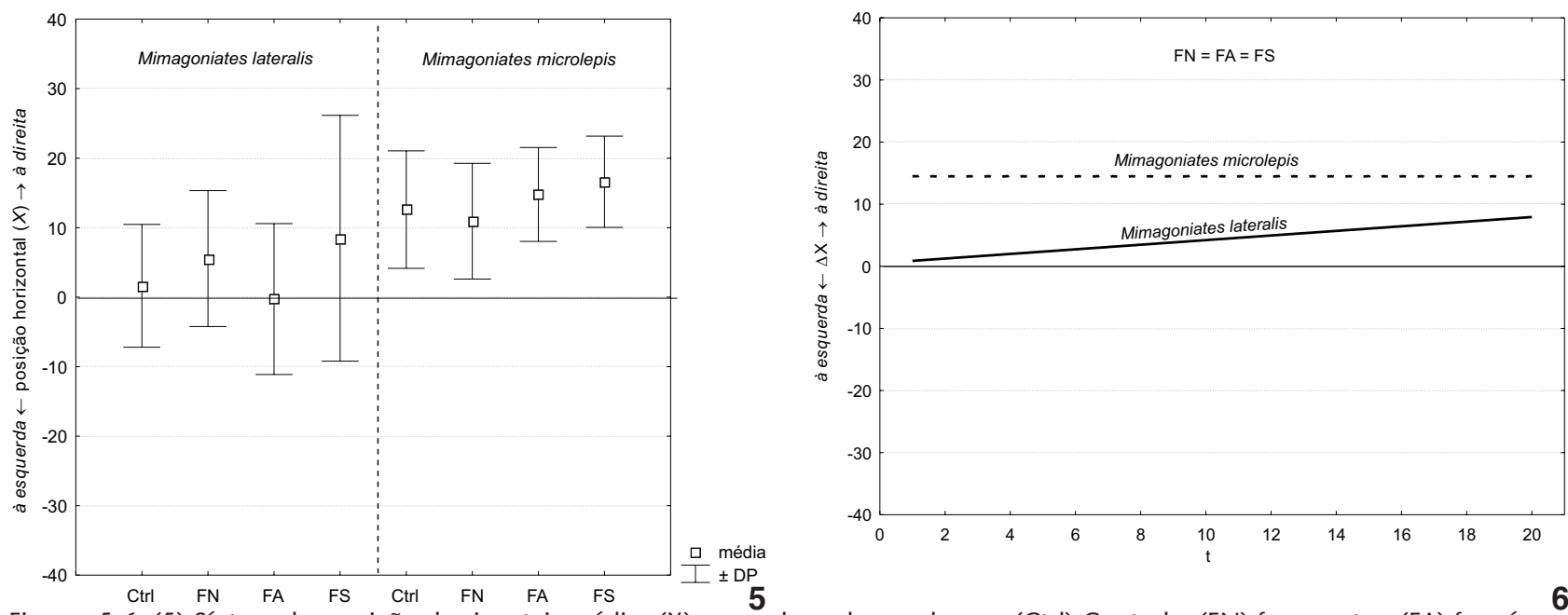

Figuras 5-6. (5) Síntese das posições horizontais médias (X) ocupadas pelos cardumes. (Ctrl) Controle, (FN) fase neutra, (FA) fase água (FS) fase susto, (DP) desvio padrão; (6) deslocamento horizontal $(\Delta \mathrm{X})$ de $M$. lateralis e $M$. microlepis interpretado através da análise de dados longitudinais. Não foram estimadas diferenças significativas entre as séries temporais das diferentes fases de cada espécie (t) tempo em "momentos": (FN) fase neutra, (FA) fase água, (FS) fase susto.

Tabela III. Posições médias estimadas para o deslocamento de $M$. lateralis (MI) e $M$. microlepis (Mm) nas direções horizontal (x) e vertical (y). A tabela mostra o número de indivíduos analisados (n) com os respectivos deslocamentos médios dentro de limites de confiança de 95\% (conf.) e as posições extremas, bem como cada desvio padrão (DP) e erro padrão (EP). (Ctrl) Controle, (FN) fase neutra, (FA) fase água, (FS) fase susto.

\begin{tabular}{|c|c|c|c|c|c|c|c|c|c|}
\hline & & $\mathrm{N}$ & Posições médias & Conf. -95\% & Conf. +95\% & Mínimo & Máximo & DP & EP \\
\hline \multirow[t]{4}{*}{ M. lateralis } & Ctrl-x & 159 & 1,6 & 0,2 & 3,0 & -24 & 27 & 8,83 & 0,701 \\
\hline & $\mathrm{FN}-\mathrm{x}$ & 40 & 5,6 & 2,4 & 8,7 & -13 & 23 & 9,78 & 1,546 \\
\hline & FA-x & 40 & $-0,3$ & $-3,7$ & 3,2 & -29 & 19 & 10,86 & 1,716 \\
\hline & FS-X & 75 & 8,5 & 4,4 & 12,5 & -26 & 32 & 17,68 & 2,042 \\
\hline \multirow[t]{4}{*}{ M. microlepis } & Ctrl-x & 159 & 12,6 & 11,3 & 13,9 & -7 & 30 & 8,45 & 0,670 \\
\hline & $\mathrm{FN}-\mathrm{x}$ & 39 & 10,9 & 8,2 & 13,6 & -9 & 25 & 8,33 & 1,333 \\
\hline & FA-X & 40 & 14,8 & 12,6 & 16,9 & 0 & 25 & 6,76 & 1,068 \\
\hline & FS-X & 78 & 16,6 & 15,1 & 18,1 & 4 & 30 & 6,56 & 0,743 \\
\hline \multirow[t]{4}{*}{ M. lateralis } & Ctrl.-y & 159 & $-31,7$ & $-32,9$ & $-30,6$ & -40 & -17 & 7,45 & 0,591 \\
\hline & FN-y & 40 & $-32,4$ & $-34,7$ & $-30,1$ & -40 & -16 & 7,14 & 1,128 \\
\hline & FA-y & 40 & $-32,3$ & $-34,6$ & $-30,0$ & -40 & -15 & 7,11 & 1,124 \\
\hline & FS-y & 75 & $-36,7$ & $-38,5$ & $-35,0$ & -40 & 10 & 7,70 & 0,889 \\
\hline \multirow[t]{4}{*}{ M. microlepis } & Ctrl.-y & 159 & $-0,1$ & $-2,1$ & 1,9 & -25 & 24 & 12,94 & 1,026 \\
\hline & FN-y & 39 & $-5,9$ & $-10,1$ & $-1,7$ & -27 & 20 & 12,99 & 2,080 \\
\hline & FA-y & 40 & 2,7 & $-1,3$ & 6,7 & -20 & 31 & 12,51 & 1,978 \\
\hline & FS-y & 78 & $-17,0$ & $-19,0$ & $-14,9$ & -32 & 19 & 9,08 & 1,028 \\
\hline
\end{tabular}

modelo para $M$. lateralis é determinada pela equação $\Delta \mathrm{X}=0,5038+(0,3713) \mathrm{t}$, enquanto a de $M$. microlepis o é pela equação $\Delta \mathrm{X}=14,50$.

Os resultados de ambas as análises convergem nas estimativas para as posições horizontais, sugerindo que as interpretações comparativas intraespecíficas dos deslocamentos neste eixo não sejam conclusivas por ambos os métodos, pois não se pode observar uma lógica causal clara para suas alterações de posição e deslocamento.

\section{Análise do deslocamento vertical}

A interpretação do deslocamento dos cardumes na direção vertical forneceu resultados mais conclusivos em todas as análi- 
ses, sendo que a ocupação espacial vertical foi claramente distinta entre as espécies (Fig. 7). Quando em situação natural, M. lateralis permaneceu mais freqüentemente próximo ao fundo do aquário, em região entre -34,7 e -30. Mimagoniates microlepis ocupou preferencialmente a meia-água, permanecendo numa posição entre 10,1 e 1,9 (figura 7 e tabela III, tendo-se em conta os valores incluídos dentro do intervalo de confiança de 95\% das fases Ctrl, FN e FA). Os cardumes das duas espécies posicionaram-se mais ao fundo quando é considerada apenas a fase FS, com M. lateralis estabelecendo-se preferencialmente entre -38,5 e -35, e M. microlepis entre -19 e -14,9 (figura 7 e tabela III, considerando-se os valores incluídos dentro do intervalo de confiança de 95\% da fase FS). Ambas as espécies demonstraram limites de movimentação bastante reduzidos nesta fase em relação às outras. Tais observações evidenciam as diferenças entre as espécies, e isto é corroborado tanto pelas análises de dados longitudinais quanto pelos testes de $\mathrm{U}$ de Mann-Whitney (Figs 7 e 8), onde todos os níveis de 'p' foram iguais a zero nas comparações M. lateralis x M. microlepis (Tab. II).

As comparações intraespecíficas das fases realizadas pela estatística não paramétrica mostraram resultados diferentes para cada espécie, mas em ambas a fase FS se mostrou distinta das demais e foi caracterizada pelo significativo deslocamento dos cardumes para o fundo do aquário experimental. O teste de $\mathrm{U}$ para $M$. lateralis não estimou diferenças significativas nas posições verticais médias entre as fases FN e FA, as quais foram significativamente diferentes da fase FS devido à tendência ao fundo ocorrida nesta, o que pode ser observado na tabela II e na figura 7.

Mimagoniates microlepis é a espécie que demonstrou maiores diferenças intraespecíficas, incluindo a estimativa de diferenças significativas entre Ctrl e FN e entre FN e FA, sendo que a comparação entre Ctrl e FA não apresentou diferenças significativas. As demais fases apresentam resultados que seriam esperados, com a fase FS sendo considerada significativamente distinta de Ctrl, FN e FA, como está ilustrado na figura 7 e detalhado na tabela II. Do mesmo modo que para a direção horizontal (o eixo X), a diferença detectada nas posições preferenciais médias entre FN e FA nesta espécie parece estar relacionada com sua reação à introdução de água no aquário experimental. Outrossim, foi observada uma diminuição na agitação dos cardumes de $M$. microlepis em FS, indicada pela queda nos valores do desvio padrão desta espécie no deslocamento vertical (Tab. III e Fig. 7).

Os dois tipos de análises mostram consistência na detecção da reação de deslocamento dos indivíduos de M. microlepis à introdução da água no aquário experimental em FA. Além de este movimento poder ser inferido a partir do gráfico da figura 7, a prova de Mann-Whitney estimou diferenças significativas entre FN e FA (Tab. II). A análise de dados longitudinais mostra diferença ainda mais clara nos comportamentos dos peixes desta espécie, cujo deslocamento está detalhado na figura 8.

As duas espécies reagiram claramente à introdução de água no aquário em FA, quando passaram a manifestar um estado de alerta que não pode ser descrito estatisticamente (Fig.
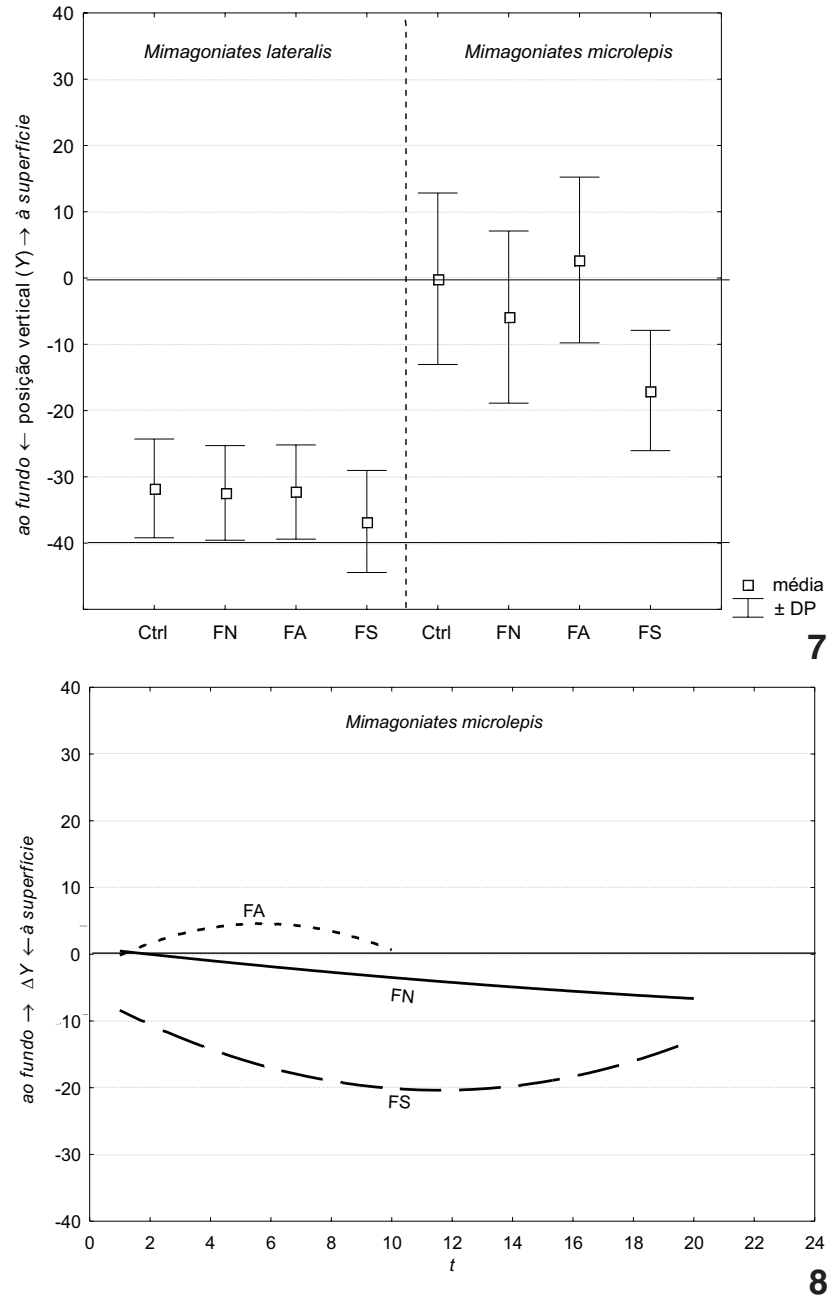

Figuras 7-8. (7) Posições verticais médias $(Y)$ ocupadas pelos cardumes; (8) deslocamento vertical $(\Delta \mathrm{Y})$ de $M$. microlepis interpretado através da análise de dados longitudinais. Foram estimadas diferenças significativas entre as séries temporais das três fases $(t)$ tempo em "momentos". (Ctrl) Controle, (FN) fase neutra, (FA) fase água, (FS) fase susto, (DP) desvio padrão.

4). Esta reação foi iniciada logo que a água foi introduzida, quando então os peixes postaram-se em cardumes sincronizados e polarizados, aumentaram o grau de compactação (vide resultados da agregação no próximo tópico) e todos os peixes voltaram-se para o lado da introdução (Fig. 4), assim permanecendo por cerca de uma hora.

A análise de dados longitudinais mostrou resultados bastante esclarecedores para a direção vertical, os quais corroboram e são complementares à interpretação obtida com os testes nãoparamétricos. As fases FN e FA já haviam sido estimadas estatisticamente semelhantes para M. lateralis nas comparações pela prova de U. Assim o foram também através da análise de dados 
longitudinais, cujo resultado determinou uma curva muito suave como modelo ajustado (Fig. 9), a qual é regida pela mesma equação do segundo grau para ambas as fases: $\Delta \mathrm{Y}=(0,0012) \mathrm{t}^{2}-$ $(0,045) t-32,18$. Este método corrobora os resultados anteriores, e indica preferência desta espécie por permanecer mais próxima ao fundo do aquário (Figs 4, 7 e 9). Da mesma maneira, a fase FS foi distinta das outras, com os peixes apresentando o comportamento de se deslocarem ainda mais para o fundo, em que o modelo ajustou uma parábola com concavidade superior determinada pela equação $\Delta \mathrm{Y}=(0,0842) \mathrm{t}^{2}-(2,307) \mathrm{t}-24,486$ (Fig. 9). Assim, no momento inicial $t=1$ o cardume estava na posição $\mathrm{Y}=-26,7$, cujo valor é aplicado na equação inicial para obter-se $-26,7=(0,0842) \mathrm{t}^{2}-(2,307) \mathrm{t}-24,486$, a qual é resolvida para $\mathrm{Y}=0$ pela equação de Bháskara. Daí se estima seu retorno à posição inicial $Y=-26,7$ em $t=26,5$, o que resulta num período de reação de $\mathrm{t} 1 \rightarrow \mathrm{t} 26,5$ (Fig. 10). Através do cálculo do vértice da parábola (como já descrito), estima-se que o cardume alcance a posição crítica $\mathrm{Y}=-40,2$ no momento $\mathrm{t}=13,7$, sendo esta a posição mais ao fundo encontrada (o vértice). Assim, M. lateralis apresentou o período de reação $\Omega \cong 26,5$ "momentos" e amplitude de reação $\Lambda \cong 13,5$ "espaços" (Fig. 10).

A espécie M. microlepis apresentou resultados ainda mais interessantes através da análise de dados longitudinais para este eixo, como pode ser observado na figura 8, e estes vêm aprimorar a compreensão dos resultados estimados pelos testes de comparações de médias. Exatamente como obtido pela prova de U de Mann-Whitney, as fases FN, FA e FS desta espécie foram consideradas distintas entre si. Semelhante à outra espécie, $M$. microlepis apresentou uma curva muito suave como modelo ajustado para a fase $\mathrm{FN}$, regida pela equação $\Delta \mathrm{Y}=(0,0066) \mathrm{t}^{2}-$ $(0,5124) t+0,9951$, demonstrando preferência por ocupar a região mais central do aquário experimental (Figs 4, 7 e 8).

Além da reação à entrada de água com um estado de alerta, manifestado por ambas as espécies, os indivíduos de $M$. microlepis reagiram com o deslocamento dos cardumes no sentido da introdução do controle (água) no aquário experimental, retornando à posição inicial após um período. Este comportamento exploratório não é uma fuga e foi detectado pela análise de dados longitudinais, para o qual o modelo ajustou uma parábola de concavidade inferior determinada pela equação $\Delta \mathrm{Y}=-(0,2134) \mathrm{t}^{2}+(2,4366) \mathrm{t}-2,3699$ (Figs 8 e 11).

Da mesma forma que $M$. lateralis, M. microlepis demonstra deslocamento para o fundo na fase FS com uma parábola de concavidade superior como modelo ajustado, mas nesta espécie regida pela equação $\Delta \mathrm{Y}=(0,1066) \mathrm{t}^{2}-(2,4734) \mathrm{t}-6,0189$ (Figs 8 e 10).

O cálculo dos componentes $\Omega$ e $\Lambda$ para a reação de alarme de $M$. microlepis determinou sua posição inicial em Y = 8,40 para $t=1$, a qual deve ser igual à final. Para a determinação do momento final, substitui-se o valor da posição inicial na equação $-8,39=(0,1066) \mathrm{t}^{2}-(2,4734) \mathrm{t}-6,0189$, onde se deve resolvê-la para $\mathrm{Y}=0$ (Bháskara). Obtém-se assim o momento final de retorno à posição inicial em $\mathrm{Y}=-8,40$, o qual foi
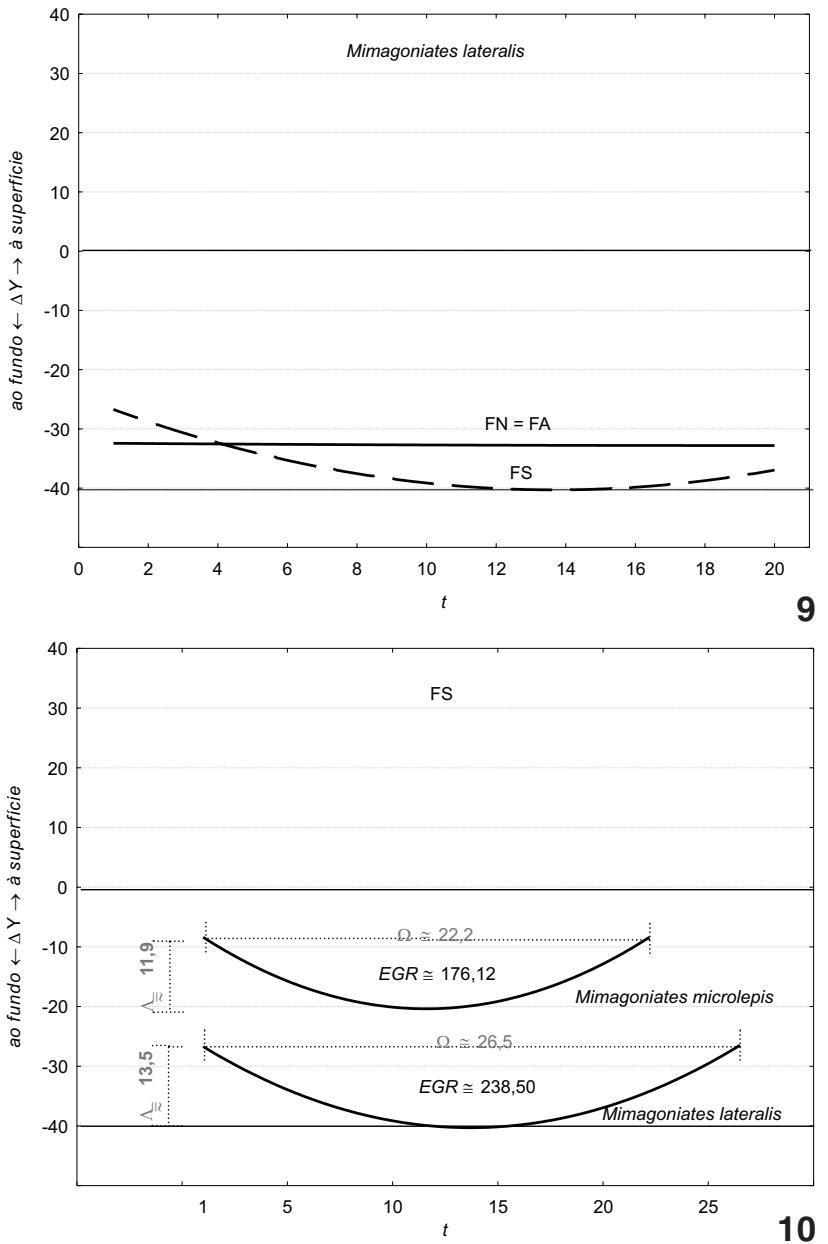

Figuras 9-10. (9) Deslocamento vertical $(\Delta Y)$ de $M$. lateralis interpretado através da análise de dados longitudinais. Não foram estimadas diferenças significativas entre as séries temporais das fases FN e FA, sendo que FS demonstrou resultado significativamente distinto de ambas (t) tempo em "momentos"; (10) comparação do componente vertical $(\Delta \mathrm{Y})$ em FS (fase susto) da reação de alarme de ambas as espécies, cujas séries temporais foram estimadas através da análise de dados longitudinais ( $\mathrm{t}$ ) tempo em "momentos". (FN) Fase neutra, (FA) fase água, (FS) fase susto, $(\Delta)$ amplitude de reação, $(\Omega)$ período de reação, (EGR) espaço gráfico de reação.

obtido em $t=22,2$, em que o período de reação está compreendido entre $t=1 \rightarrow t=22,2$. Neste caso, o deslocamento crítico foi alcançado no momento $t=11,6$ (vértice da parábola), obtido na posição $\mathrm{Y}=-20,3$, cujos resultados permitem estimar-se que a reação de alarme desta espécie possua $\Omega=22,2$ e $\Lambda=$ 11,9, como ilustrado na figura 10 .

Finalmente, também se pode estimar $\Omega$ e $\Lambda$ de $M$. microlepis relativos a sua reação à introdução do controle (água) em FA. Assim, a posição inicial $(t=1)$ dos cardumes em FA foi 
calculada em $\mathrm{Y}=-0,15$. Aplicando-se este valor à equação e resolvendo-a para $\mathrm{Y}=0$, tem-se $-0,15=-(0,2134) \mathrm{t}^{2}+(2,4366) \mathrm{t}$ $-2,3699$, onde uma das raízes é $t=10,4$, valor que representa o momento onde o cardume retorna à posição inicial relativo a $\mathrm{Y}=-0,15$. Isto resulta num período de reação de aproximadamente $\mathrm{t}=1 \rightarrow \mathrm{t}=10,4$, como pode ser observado na figura 11 . O deslocamento crítico é determinado no vértice da parábola da mesma maneira descrita anteriormente, o qual foi estimado na posição $\mathrm{Y}=4,6$ para o momento $t=5,7$, e assim se obtém-se os parâmetros $\Omega \cong 10,4$ e $\Lambda \cong 4,7$ para a FA da população estudada (Fig. 11).

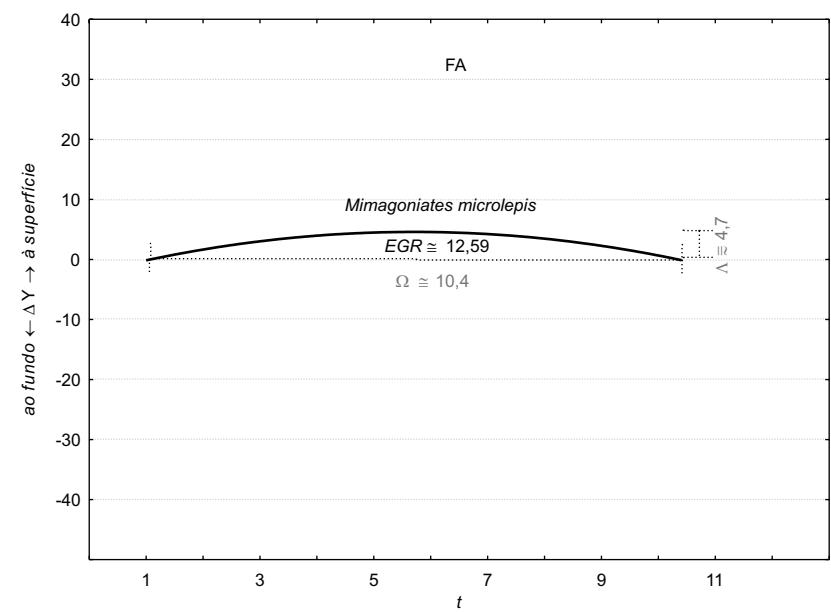

Figura 11. Interpretação do componente vertical $(\Delta \mathrm{Y})$ da reação à introdução da água em FA (fase água) por M. microlepis, cuja série temporal foi estimada através da análise de dados longitudinais (t) tempo em "momentos": (FN) fase neutra, (FA) fase água, (FS) fase susto, $(\Lambda)$ amplitude de reação, $(\Omega)$ período de reação, (EGR) espaço gráfico de reação.

\section{Análise da agregação dos peixes (coesão dos cardumes)}

A análise da coesão dos cardumes forneceu resultados claros e objetivos, os quais demonstraram diferenças significativas em ambas as espécies (Tab. V). Tais estimativas foram obtidas tanto para as comparações interespecíficas relativas a todas as fases, como para as intraespecíficas entre a fase FS e as demais. A figura 12 ilustra os resultados obtidos para dispersão (IDC) e agregação (TAC) nos cardumes em cada fase para as duas espécies.

Constatou-se ausência de diferenças significativas na agregação dos cardumes entre Ctrl e fase FN em cada espécie, enquanto a fase FS foi considerada distinta em ambas (Tab. IV e Fig. 12). Os cardumes estiveram mais agregados nesta fase do que nas demais.

Quando os resultados estimados da agregação em cada fase de uma espécie são comparados com seus análogos da outra, todos demonstram diferenças significativas. Isto também
Tabela IV. Testes de U de Mann-Whitney para as análises comparativas do índice de dispersão nos cardumes (IDC) e da taxa de compactação dos cardumes (TAC), demonstrando os valores de $U$ e de Z. ( $\left.{ }^{*}\right)$ Significativo $(p<0,05)$, (ns) não significativos ( $p$ $\geqslant 0,05)$ para as respectivas amostras $(n)$, (Ctrl) controle, (FN) fase neutra, (FA) fase água, (FS) fase susto.

\begin{tabular}{|c|c|c|c|c|c|}
\hline Dispersão (IDC) & U & Z & $p$ & $\mathrm{n}_{1}$ & $\mathrm{n}_{2}$ \\
\hline \multicolumn{6}{|l|}{ M. lateralis } \\
\hline Ctrl $\times \mathrm{FN} \mathrm{ns}$ & 14702,00 & $-1,150$ & 0,239 & 159 & 199 \\
\hline Ctrl $\times$ FA ns & 2980,50 & 0,613 & 0,530 & 159 & 40 \\
\hline Ctrl $\times$ FS * & 3765,50 & 4,421 & 0,000 & 159 & 74 \\
\hline $\mathrm{FN} \times \mathrm{FA} \mathrm{ns}$ & 3477,00 & 1,261 & 0,198 & 199 & 40 \\
\hline $\mathrm{FN} \times \mathrm{FS}$ * & 4403,00 & 5,105 & 0,000 & 199 & 74 \\
\hline$F A \times F S$ * & 1036,50 & 2,633 & 0,007 & 40 & 74 \\
\hline \multicolumn{6}{|l|}{ M. microlepis } \\
\hline Ctrl $\times \mathrm{FN} \mathrm{ns}$ & 14841,00 & $-0,929$ & 0,334 & 159 & 198 \\
\hline Ctrl $\times$ FA ns & 2879,00 & $-0,924$ & 0,337 & 159 & 40 \\
\hline Ctrl $\times$ FS * & 4311,00 & 3,811 & 0,000 & 159 & 78 \\
\hline $\mathrm{FN} \times \mathrm{FA} n \mathrm{n}$ & 3796,00 & $-0,413$ & 0,667 & 198 & 40 \\
\hline $\mathrm{FN} \times \mathrm{FS}$ * & 4920,00 & 4,693 & 0,000 & 198 & 78 \\
\hline $\mathrm{FA} \times \mathrm{FS}$ * & 965,50 & 3,380 & 0,001 & 40 & 78 \\
\hline \multicolumn{6}{|c|}{ M. lateralis $\times M$. microlepis } \\
\hline Ctrl * & 1176,00 & $-13,985$ & 0,000 & 159 & 159 \\
\hline $\mathrm{FN}$ * & 1741,00 & $-15,711$ & 0,000 & 199 & 198 \\
\hline $\mathrm{FA}$ * & 61,00 & $-7,111$ & 0,000 & 40 & 40 \\
\hline FS * & 369,00 & $-9,278$ & 0,000 & 74 & 78 \\
\hline Agregação (TAC) & $U$ & Z & $\mathrm{p}$ & $\mathrm{n}_{1}$ & $\mathrm{n}_{2}$ \\
\hline \multicolumn{6}{|l|}{ M. lateralis } \\
\hline Ctrl $\times$ FN ns & 15577,50 & 0,254 & 0,800 & 159 & 199 \\
\hline Ctrl $\times$ FA ns & 2819,00 & $-1,122$ & 0,262 & 159 & 40 \\
\hline Ctrl $\times$ FS * & 3415,50 & $-5,792$ & 0,000 & 159 & 74 \\
\hline $\mathrm{FN} \times \mathrm{FA} \mathrm{ns}$ & 3477,00 & $-1,289$ & 0,198 & 199 & 40 \\
\hline $\mathrm{FN} \times \mathrm{FS}$ * & 4204,00 & $-6,155$ & 0,000 & 199 & 74 \\
\hline$F A \times F S$ * & 996,50 & $-3,348$ & 0,001 & 40 & 74 \\
\hline \multicolumn{6}{|l|}{ M. microlepis } \\
\hline Ctrl $\times \mathrm{FN} \mathrm{ns}$ & 15819,00 & $-0,086$ & 0,932 & 159 & 198 \\
\hline Ctrl $\times$ FA ns & 3037,00 & 0,451 & 0,652 & 159 & 40 \\
\hline Ctrl $\times$ FS * & 3931,50 & $-4,678$ & 0,000 & 159 & 78 \\
\hline $\mathrm{FN} \times \mathrm{FA} n \mathrm{~s}$ & 3760,00 & 0,574 & 0,566 & 198 & 40 \\
\hline $\mathrm{FN} \times \mathrm{FS}$ * & 5074,50 & $-4,643$ & 0,000 & 198 & 78 \\
\hline $\mathrm{FA} \times \mathrm{FS}$ * & 965,50 & $-3,476$ & 0,001 & 40 & 78 \\
\hline \multicolumn{6}{|c|}{ M. lateralis $\times M$. microlepis } \\
\hline Ctrl * & 1037,50 & 14,228 & 0,000 & 159 & 159 \\
\hline $\mathrm{FN}$ * & 2139,00 & 15,588 & 0,000 & 199 & 198 \\
\hline $\mathrm{FA}$ * & 61,00 & 7,176 & 0,000 & 40 & 40 \\
\hline FS * & 292,50 & 9,892 & 0,000 & 74 & 78 \\
\hline
\end{tabular}





Figura 12. Comportamento de coesão dos peixes nos cardumes de cada espécie e para cada fase de análise em ambas as baterias experimentais. (Ctrl) Controle, (FN) fase neutra, (FA) fase água, (FS) fase susto, (DP) desvio padrão, (IDC) índice de dispersão dos peixes nos cardumes, (TAC) taxa de agregação dos peixes nos cardumes, em porcentagem.

pode ser observado na figura 12 e está discriminado na tabela IV. Os cardumes de M. lateralis demonstraram TAC $\%$ entre $50 \%$ e $60 \%$ durante as fases Ctrl, FN e FA, com dispersão (IDC) média dos peixes por 5,1 a 5,4 quadros, enquanto os cardumes de M. microlepis demonstraram TAC\% entre $13 \%$ e $21 \%$, com dispersão média por 8,3 a 8,5 quadros nestas mesmas fases (Tab. V). Cada espécie demonstrou comportamento de agregação distinto da outra, de acordo com as estimativas dos testes de Mann-Whitney. Todos os resultados foram significativos na comparação do TAC entre ambas as espécies (Tab. IV).

A fase FS foi caracterizada para as duas espécies pela menor coesão de seus cardumes, com os peixes permanecendo menos dispersos. Neste caso, os cardumes de M. lateralis apresentaram dispersão média de 4,4 quadros e TAC\% em 62,6\% \pm 17,89 , enquanto os de $M$. microlepis apresentaram dispersão média de 7,6 quadros e TAC $\%$ de $26 \% \pm 13,40$. A análise comparativa interespecífica do comportamento também sugere que as espé- cies apresentam agregações diferentes nesta fase, com os valores de TAC apresentando diferenças significativas. Importante observar que $M$. lateralis demonstrou aumentar em cerca de $15 \%$ a coesão de seus cardumes na fase FS em relação à média das outras, enquanto M. microlepis compactou seus cardumes ainda mais, demonstrando um aumento da coesão em cerca de $30 \%$ (Tab. V). Também é interessante notar que M. lateralis apresentou ligeiro aumento no desvio padrão relativo à coesão nesta fase, o que não foi observado em M. microlepis (Tab. V).

\section{Intensidade de reação}

As reações observadas foram interpretadas matematicamente e puderam ser representadas graficamente por funções parabólicas, e assim pôde-se calcular a intensidade de reação (i) de uma maneira sistematizada. Desta forma, a intensidade

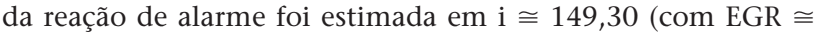
238,50 ) para $M$. lateralis e $\mathrm{i} \cong 46,14$ (com $\mathrm{EGR} \cong 176,12$ ) para M. microlepis (Fig. 10).

O mesmo conceito foi aplicado na interpretação da reação de M. microlepis à introdução de água na fase FA, cujo resultado foi obtido com a intensidade desta reação sendo estimada em $\mathrm{i} \cong 5,51$, para $\mathrm{EGR} \cong 32,59$ (Fig. 11).

\section{DISCUSSÃO}

Embora as duas espécies aqui estudadas sejam simpátricas e ocorram em uma mesma ecorregião, raramente são encontradas em sintopia (SchulTz 1959), ocupando normalmente províncias (sensu Magurran \& Pitcher 1987) e habitats muito distintos (Weitzman et al. 1988). Ambas demonstraram clara diferenciação comportamental quanto às preferências por posição e compactação dos cardumes, particularmente quanto às diferenças na intensidade da reação (i). Diferenças na Schreckreaktion entre diferentes espécies são de fato esperadas (Pfeiffer 1977, SMITH 1977).

WaLdman (1982) estudou a RA do ciprinídeo Danio rerio (Hamilton, 1822) (Cyprinidae), embora não tenha analisado a agregação ou a intensidade da reação, e encontrou tendências posicionais semelhantes às aqui obtidas: nenhum resultado significativo no componente horizontal $\mathrm{X}$ e tendência ao fundo no vertical Y. Ele sugeriu como causa destes resultados uma possível dispersão diferenciada da SA no aquário, a qual ocorreria mais rapidamente no eixo Y do que no X. Entretanto, o desenho experimental aqui executado não permite tal interpretação, visto haver circulação permanente da água no aquário. Além disso, foram realizados testes prévios com a introdução de uma solução indicadora de azul de metileno através do tubo de alarme e em condições experimentais, cujos resultados demonstraram haver rápida dispersão por todo o meio e em todas as direções.

Quando em situação normal no aquário (Ctrl ou FN), os exemplares estudados de M. microlepis manifestaram comportamento com elementos semelhantes ao observado no ambiente natural, como a ocorrência de cardumes mais movimentados e menos coesos, postados sempre mais à superfície. Poder-se-ia considerar este comportamento como dentro do esperado, uma vez que é uma espécie reconhecidamente comedora de superfí- 
Tabela V. Estimativas de variação dos valores da agregação dos cardumes de $M$. lateralis e $M$. microlepis. A tabela mostra o número de indivíduos analisados (n) com os respectivos valores médios para o índice de dispersão nos cardumes (IDC) e taxa percentual de agregação nos cardumes (TAC\%), com sua faixa de variação dentro de limites de confiança de $95 \%$ (conf.) e os valores extremos, bem como cada desvio padrão (DP) e erro padrão (EP). (Ctrl) Controle, (FN) fase neutra, (FA) fase água, (FS) fase susto.

\begin{tabular}{|c|c|c|c|c|c|c|c|c|c|}
\hline & \multirow{2}{*}{$\mathrm{n}$} & \multirow{2}{*}{ IDC médio } & \multicolumn{7}{|c|}{ TAC\% } \\
\hline & & & Média & Conf. $-95 \%$ & Conf. $+95 \%$ & Mínimo & Máximo & DP & EP \\
\hline \multicolumn{10}{|c|}{ M. lateralis } \\
\hline Ctrl & 159 & 5,2 & 52,9 & 51 & 55 & 22 & 89 & 14,33 & 1,137 \\
\hline $\mathrm{FN}$ & 199 & 5,4 & 51,2 & 49 & 53 & 11 & 89 & 15,38 & 1,090 \\
\hline FA & 40 & 5,1 & 54,7 & 50 & 60 & 22 & 89 & 15,59 & 2,465 \\
\hline FS & 74 & 4,4 & 62,6 & 58 & 67 & 0 & 89 & 17,89 & 2,079 \\
\hline \multicolumn{10}{|c|}{ M. microlepis } \\
\hline Ctrl & 159 & 8,3 & 18,9 & 17 & 21 & 0 & 56 & 12,67 & 1,005 \\
\hline $\mathrm{FN}$ & 198 & 8,4 & 17,4 & 16 & 19 & 0 & 44 & 11,71 & 0,832 \\
\hline FA & 40 & 8,5 & 16,9 & 13 & 21 & 0 & 56 & 13,31 & 2,105 \\
\hline FS & 78 & 7,6 & 26,2 & 23 & 29 & 0 & 67 & 13,40 & 1,517 \\
\hline
\end{tabular}

cie (Nelson 1964, Sabino \& Castro 1990, Mazzoni \& Iglesias-Rios 2002, LAMPERT et al. 2003), e interpretá-lo como um indicativo de baixos níveis de estresse. Por outro lado, os exemplares de $M$. lateralis manifestaram comportamento aparentemente distinto do natural, demonstrando pouca aclimatação ao aquário experimental (cujo ambiente é bem diferente do seu natural). Os peixes desta espécie se mostraram mais ariscos a perturbações externas, permanecendo em cardumes menos movimentados e bem mais coesos, situados no centro e mais ao fundo do aquário na maior parte do tempo. Muito pouco se conhece sobre a ecologia de M. lateralis, mas estudos em andamento, observações em campo e umas poucas considerações tecidas por NeLSON (1964) levam a crer que esta espécie também seja uma comedora de superfície, e deste modo seu comportamento poderia estar indicando níveis de estresse mais elevados.

$\mathrm{O}$ ambiente do aquário experimental é mais parecido com o ambiente natural de M. microlepis principalmente por causa da baixa opacidade da água dos aquários em que os peixes foram mantidos (oriunda de riachos da Serra do Mar), mas também devido à ausência dos bancos de vegetação normalmente utilizados como abrigo por M. lateralis. Isto pode estar influenciando a pronunciada disparidade comportamental demonstrada entre o ambiente natural e o aquário experimental por esta espécie.

Mimagoniates microlepis reagiu à entrada de água no aquário experimental em FA demonstrando comportamento de investigação/inspeção (CsANYI 1985). Entretanto, esta foi uma reação muito menos intensa e completamente distinta de sua RA (Fig. 8). O fluxo de água pelo tubo do alarme é da ordem de 50 $\mathrm{ml} / \mathrm{min}$., o que causa uma corrente claramente percebida por ambas as espécies (tornada visível nos pré-testes com solução de azul de metileno). Logo após a introdução de água as duas espécies imediatamente sincronizaram e polarizaram os cardumes (Fig. 4), mas apenas M. microlepis reagiu apresentando também deslocamento no sentido do influxo.
O aquário experimental não possui sistema de renovação contínua da água (embora possua circulação constante), e a qualidade desta não pode ser comparada à da água sempre renovada e oxigenada dos riachos do ambiente natural de $M$. microlepis. Talvez esta seja uma das causas da comum aglomeração dos peixes desta espécie na entrada d'água, os quais interagem também com a forte corrente formada pela pressão da mangueira quando da limpeza ou troca de água dos aquários-estoque. Os indivíduos de $M$. microlepis são claramente atraídos pela correnteza enquanto M. lateralis não, e estas diferenças no comportamento podem ser peculiaridades associadas à adaptação destas espécies aos diferentes meios onde ocorrem.

O posicionamento dos peixes é determinado por pontos de referência associados à visão e/ou linha lateral, os quais são dois importantes sistemas de orientação também envolvidos na determinação e controle de território e espaço. Destes, o sistema acústico-lateral é particularmente sensível nos peixes de cardume, nos quais exerce papel determinante sobre o comportamento de encardumar (Moyle \& Cech 1988, Pitcher \& ParRish 1993). A formação de cardumes é decisiva na proteção de várias espécies e particularmente importante nas aqui estudadas (Keenleyside 1955, Nelson 1964, Partridge 1982, Pitcher \& MagurRan 1983, Magurran 1990), sendo que exemplares isolados ou em pequenos grupos (e.g. menos que cinco indivíduos) demonstraram comportamento muito distinto de quando observados em cardumes (tornando-se mais ariscos e parados no centro do aquário). A formação dos cardumes, bem como a determinação do número de indivíduos e sua compactação, é contexto-dependente e está associada à otimização da relação custo-benefício adaptada ao longo do processo evolutivo (HOARE et al. 2004). O nível de compactação dos cardumes está estreitamente associado à eficiência do escape, uma vez que o aumento da coesão parece estar diretamente relacionado ao aumento da velocidade de comunicação entre os peixes (KRAUSE 
\& Tegeder 1994). Este padrão de comunicação baseia-se na interpretação das ondas de pressão pelo sistema acústico-lateral e atua diretamente no aumento da velocidade de sincronização dos peixes, com conseqüente melhora na performance das manobras de evasão (Gray \& Denton 1991).

Assim, seria esperado um aumento na coesão dos peixes quando sob alarme (Fig. 4) ou mesmo em ambiente desconhecido ou hostil (HoARe et al. 2004), embora não se conheça tais detalhes na situação normal destas espécies em seu ambiente natural. Não por acaso ambas as espécies demonstraram significativa compactação dos cardumes quando expostas à SA, bem como M. lateralis apresentou cardumes geralmente três vezes mais compactos do que M. microlepis em todas as situações (Tab. V). Tais resultados são coerentes com a ecologia das espécies, pois podem estar de alguma forma associados ao fato de M. lateralis ser uma espécie de alto endemismo geográfico e ecotópico (Weitzman et al. 1988, Menezes \& Weitzman 1990), e ameaçada de extinção (MACHADo et al. 2005), aparentemente sendo muito exigente quanto à qualidade ambiental. Por outro lado, M. microlepis é uma espécie de ampla distribuição geográfica (WEITZMAn et al. 1988, Menezes \& Weitzman 1990, Ingenito et al. 2004, Sant'Anna et al. 2006) e com flexibilidade trófica (Esteves \& Lobón-Cerviá 2001, MAZzoni \& Rezende 2003, LAMPERT et al. 2003), sendo aparentemente mais plásticos à qualidade ambiental. Vale lembrar que esta espécie demonstra flexibilidade ecotópica muito maior que a outra, pois além de ocorrer em uma extensa área do litoral brasileiro, tem sido registrada também nas bacias do rio Iguaçu (Ingenito et al. 2004, Abilho 2005) e do rio Tibagi (SANT'Anna et al. 2006), bacias distintas e cujos ambientes não são os mesmos dos riachos litorâneos de sua ocorrência primária (embora algo semelhantes). Além disso, quando estas espécies foram observadas em sintopia, foi sempre M. microlepis que ocorreu no ambiente de M. lateralis, nunca o contrário.

\section{Avaliação ecológica e comparativa da reação de alarme}

Há várias limitações impostas às análises de comportamento por questões de viabilidade, as quais podem influenciar o comportamento normal dos indivíduos e/ou cardumes (HoARe et al. 2004), ou até mesmo alterar as respostas ou a produção da substância de alarme, como ponderou Pfeiffer (1963b). As dificuldades de interpretação são agravadas pelo conhecimento ainda insuficiente sobre a distribuição das CSA e SA ou a efetividade da RA dos Ostariophysi em ambiente natural (SMITH 1982, MAGURRAN et al. 1996, WiSENDEN et al. 2004). Alguns padrões de influências já foram estudados em outros grupos, os quais muitas vezes podem se associar àqueles relacionados à manutenção em aquário e prejudicar sua interpretação. Aspectos nutricionais (FRISCH 1941, Smith 1981, Pfeiffer 1962) ou a redução sazonal do número de CSA nos períodos reprodutivos de algumas espécies (Sмiтн 1973, 1976, 1977, 1986, Sмiтн \& Sмiтн 1983, 1986) parecem atuar na redução da capacidade de reação, que em alguns casos pode ser apenas temporariamente perdida (SмITH 1982, 1983).

Os resultados das análises em aquário demonstraram que a RA possui componentes semelhantes em M. lateralis e M. microlepis, como o aumento na coesão dos peixes dentro de cardumes postados em "forma de bola" ("ball shape", Pitcher \& PArrish 1993), seguido pela efetuação de sacudidas rápidas e aleatórias ("skittering") e busca por abrigo no fundo ("bottom hiding", Magurran \& Pitcher 1987). Entretanto, possui elementos suficientes para distingui-las, como indicam as significativas diferenças encontradas entre os três componentes do comportamento de alarme aqui analisados: $\Omega, \Lambda$ e TAC. Estes resultaram na pronunciada diferença de intensidade nas reações de alarme observadas entre as duas espécies, com $M$. lateralis apresentando maiores valores de agregação (TAC), amplitude $(\Lambda)$ e período de reação $(\Omega)$.

Mimagoniates lateralis demonstrou possuir uma reação de alarme com intensidade cerca de três vezes maior que a de $M$. microlepis, principalmente determinada pelo componente vertical Y e pela compactação dos cardumes (TAC), sendo que $M$. lateralis já apresenta cardumes cerca de três vezes mais compactados que M. microlepis em condições normais de aquário. Pode-se observar que enquanto o espaço de reação (EGR) de $M$. lateralis é apenas 1,35 vezes maior do que $M$. microlepis (Fig. 10), sua intensidade de reação (i) é cerca de 3,24 vezes maior ( $\mathrm{i} \cong 149,30$ versus $\mathrm{i} \cong 46,14$ ), o que reforça a importância de se incluir o componente compactação dos cardumes (TAC) nos cálculos da intensidade de reação.

BRown et al. (2000) afirmam que o sistema químico de alarme dos Ostariophysi pode ser bastante afetado pela alteração estrutural do 3(N)-Óxido de hipoxantina causada pela ação da acidez sobre o grupo [NO]. Desta forma, presume-se que a grande acidez natural do ambiente onde $M$. lateralis possui ocorrência endêmica (Weitzman et al. 1988) seja um aspecto que possa afetar de alguma forma os resultados obtidos. Brown et al. (2000) citam como exemplo a ausência de reação do ciprinídeo Pimephales promelas Rafinesque, 1820 (Cyprinidae) quando mantido em pH 6,0, embora a apresente normalmente quando em $\mathrm{pH} 7,5$. Uma vez que o ambiente natural de $M$. lateralis frequentemente apresente $\mathrm{pH} 3,9$, tais afirmações colocariam em dúvida a eficiência ou apresentação da RA por esta espécie em seu meio natural. Este fato também poderia estar potencializando o estresse causado pela SA no aquário, além de levar ao questionamento sobre a adaptabilidade deste sistema químico em ambientes ácidos. De qualquer modo, há necessidade de maiores estudos sobre a natureza da influência da acidez sobre a ecologia das espécies, bem como sobre a ação da RA em ambiente natural.

Os conjuntos de estratégias efetuadas sob alarme tendem a ser altamente específicas, ou seja, peculiares a cada espécie e freqüentemente proporcionais à distância filogenética entre elas (SChutz 1956, SMith 1986, Chivers \& SMith 1998, Brown et al. 2000, 2003), embora também sofram influências adaptativas contextualizadas a suas relações ecológicas com o hábitat (НЕсzко \& Seghers 1981, Gazdewich \& Chivers 2002, Hoare et al. 2004). No entanto, o status taxonômico de M. microlepis é ainda questionável (Menezes \& Weitzman 1990), podendo conter mais de uma espécie, o que levaria a interpretações diferentes dos resultados

Revista Brasileira de Zoologia 24 (4): 1163-1185, dezembro 2007 
obtidos. Estes parecem convergir para a idéia de complexo específico (ou ao menos não a negam), uma vez que esta espécie tenha demonstrado reação menos intensa e maiores variações comportamentais quando comparados aos resultados muito mais estritos de M. lateralis. Por outro lado, estes resultados mais estritos podem estar associados ao fato de M. lateralis ser uma espécie de alta endemicidade, a qual demonstrou comportamento pouco natural em aquário, com indivíduos mais estressados e ariscos. Assim, seria lógico esperar que a reação de alarme desta espécie também fosse mais intensa.

A grande diferença da intensidade de reação (i) obtida para as duas espécies analisadas deve ser analisada à luz de estudos recentes, os quais vêm implementar sua interpretação taxonômica (Menezes \& Weitzman 1990, Weitzman \& Menezes 1998, CASTro et al. 2003) e macroecológica (WeitzMAn et al. 1988, LAMPERT et al. 2003, IngENito et al. 2004, SANT'ANNA et al. 2006). Desta forma, M. microlepis, a espécie mais generalista e oportunista, pareceu mais flexível e mais adaptável às condições experimentais, embora as condições do aquário fossem mais semelhantes à de seu ambiente natural. As várias sub-populações desta espécie poderiam ser testadas independentemente quanto à reação de alarme, e com isso contextualizar-se sua(s) RA no âmbito da espécie. Por outro lado, M. lateralis, a espécie ecologicamente mais estrita, demonstrou ser também a mais estressada e de reação mais intensa. Mimagoniates lateralis vem demonstrando ser uma espécie muito exigente de qualidade ambiental, o que é observado em feições como ocorrência ecotópica restrita, distribuição endêmica e até o comportamento, segundo os resultados aqui obtidos.

A intensidade da reação (incluindo $\Lambda$ e $\Omega$ ) e a freqüência com que ocorre interferem diretamente na viabilidade ecológica da espécie (ou população), pois os indivíduos reduzem ou interrompem atividades essenciais de seus ciclos de vida durante o período em que estão sob o efeito do alarme, tais como alimentação e reprodução, bem como aumentam sobremaneira os níveis de estresse (FrISCH 1938, SMITH 1977, 1982, 1986, JAKOBSEN \& Johnsen 1989, Volpato et al. 2006). O fato de M. lateralis demonstrar uma RA mais intensa, longa e talvez mais freqüente, sugere possibilidade da ocorrência de estresse prolongado ou mais freqüente também em ambiente natural. Isso poderia levar a relação custo-benefício relativa à efetividade da RA a um balanço negativo, tornando-se mais um fator entre os que contribuem para a espécie encontrar-se ameaçada de extinção.

É interessante avaliar-se estes aspectos de forma contextualizada, pois a região litorânea do Brasil é a que mais vem sofrendo os impactos da colonização humana nos últimos 500 anos. A intensa ocupação associada ao uso descontrolado do meio acabou levando a Floresta Atlântica ao status de um dos biomas mais ameaçados do planeta, bem como em um dos ambientes com maior quantidade de espécies ameaçadas. Esta região inclui a área primária de distribuição das espécies em questão, a qual vem sofrendo profundas alterações relativas à poluição aquática por esgotamento doméstico, desmatamento da vegetação ripária e assoreamento dos corpos d'água, entre outros (Aвilhoa \& Duboc 2004). Tais impactos podem, por exemplo, prejudicar diretamente a quimiorrecepção das espécies aquáticas através do aumento da acidez dos corpos d'água oriundos da poluição, da mesma forma que o desmatamento elimina recursos alimentares e o assoreamento destrói sítios reprodutivos. Todos os fatores sinergem na qualidade ambiental, fundamental para a conservação das espécies.

\section{Avaliação metodológica}

Apesar de não ter havido oportunidade de se testar experimentalmente a interferência real dos fatores relacionados à manutenção sobre os animais utilizados, é oportuno esclarecer quatro pontos: a) a luminosidade foi mantida constante e igual para ambas as espécies, enquanto na natureza os níveis de luminosidade são distintos devido a diferenças na cor e transmitância da água; b) os aquários não possuíam sistema de renovação de água, o que ocorre no ambiente natural em maior escala para M. microlepis_e menor para M. lateralis; c) o pH da água foi mantido próximo do neutro em todos os aquários, pois é muito difícil sua manutenção em níveis de acidez muito altos sem prejuízo de outras qualidades (e.g. oxigenação), mas os níveis ambientais de $\mathrm{pH}$ são reconhecidamente muito diferentes entre as duas espécies.

A opção por uma criação equalizada de ambas as espécies pode ser vista de duas formas: a) a manutenção equânime das espécies facilitaria as comparações interespecíficas por igualar os meios, já que assim aumentam as probabilidades de as distinções reveladas serem principalmente ligadas aos aspectos fenotípicos próprios a cada espécie ou grupo; b) a manutenção equânime mascararia as diferenças fenotípicas devido a uma possível convergência induzida pela plasticidade dos fenótipos, levando-se em conta a marcada diferença de habitats entre estas espécies.

O desenho experimental proposto e a metodologia aplicada, bem como as análises estatísticas aplicadas, demonstraram grande eficiência na detecção qualitativa e quantitativa do comportamento dos cardumes das duas espécies em aquário, podendo ser considerados de utilização bem sucedida e sugerida para estudos futuros. Considera-se fundamental que as análises comportamentais das espécies que possuem o hábito de encardumar sejam realizadas com os indivíduos em cardumes, pois os peixes mostram comportamentos muito distintos quando isolados ou em grupos muito pequenos em relação ao natural, como foi observado nos pré-testes e já discutido em HoAre et al. (2004).

Uma das principais expectativas deste trabalho era formular uma maneira objetiva e sistematizada de descrever a RA da espécies e então distingui-las através dela. O objetivo foi alcançado através do estudo detalhado dos fatores $\Lambda, \Omega$ e TAC. Estes três componentes, quando analisados em conjunto, permitiram a interpretação da intensidade de reação (i), seja a própria do alarme ou à introdução de água no aquário. Desta forma, foi possível a determinação mais abrangente, robusta, ob-

Revista Brasileira de Zoologia 24 (4): 1163-1185, dezembro 2007 
jetiva e sistematizada da intensidade da reação em relação à forma inicialmente arbitrada por FRISCH (1941), para a qual já eram esperados estágios intermediários no continuum comportamental (Pfeiffer 1962). Os resultados foram reforçados pela possibilidade das análises cruzadas de estatística e interpretação gráfica com as observações diretas.

A proposta de cálculo para a análise de agregação (TAC) demonstrou eficiência e utilidade na compreensão do estado natural e em alarme, bem como a utilização da análise de dados longitudinais foi fundamental para a detecção das preferências posicionais e dos componentes período $(\Omega)$ e amplitude $(\Lambda)$ de reação. A utilização da prova de 'U' de Mann-Whitney, de ampla utilização em análises desta natureza, veio corroborar os resultados obtidos pelos outros métodos, bem como auxiliar na compreensão detalhada dos comportamentos entre as fases e entre as espécies.

Assim, a sistematização matemática e gráfica aqui proposta para a avaliação da intensidade de reação 'i' demonstrou-se válida e forneceu resultados comparáveis, cuja objetividade poderá redundar em outras aplicações. Desta forma, os resultados das avaliações assim obtidas poderiam ser empregados, por exemplo, em avaliações ambientais ou como aspectos acessórios nas análises sistemáticas, uma vez que as RA parecem possuir alguma relação com a distância filogenética entre as espécies.

\section{AGRADECIMENTOS}

Este estudo está fundamentado no trabalho realizado como requisito parcial à obtenção do título de Mestre em Zoologia pela Universidade Federal do Paraná, no que sou especialmente grato a meu orientador Paulo T.C. Chaves e aos então coordenadores do Curso de Pós-Graduação em Zoologia, Setuko Masunari e Walter A.P. Boeger. Foi imprescindível a colaboração de Gislaine Otto nos trabalhos, bem como a dos colegas Eloísa Wistuba, Flávio Popazoglo e André L.P. Côrtes, pelos auxílios em campo e em laboratório. Agradeço a Sandra D.R. Marcelino e Paulo R.B. Guimarães pela realização das análises de dados longitudinais. O abstract foi revisado e substancialmente implementado por Vinícius Abilhoa, pelo que sou especialmente grato. Os trabalhos contaram com auxílio do CNPq (Processo 830349/94-4 NV).

\section{REFERÊNCIAS BIBLIOGRÁFICAS}

AbilhoA, V. 2005. Ictiofauna, p. 437-456. In: C.V. Andreoli \& C. CARNEIRo. Gestão integrada de mananciais de abastecimento eutrofizados. Curitiba, Ed. Gráfica Capital, 500p.

Aвilhoa, V. \& L.F. Duboc. 2004. Peixes, p. 581-677. In: S.B. Мiкich \& R.S. BérnILS (Eds). Livro Vermelho dos animais ameaçados de extinção no estado do Paraná. Curitiba, Mater Natura e Instituto Ambiental do Paraná. XVI+764p.

Böhlke, J.E.; S.H. Weitzman \& N.A. Menezes. 1978. Estado atual da sistemática dos peixes de água doce América do Sul. Acta Amazônica 8 (4): 657-677.
Brasil. 2006. Plano Nacional de Recursos Hídricos. Panorama e estado dos recursos hídricos do Brasil -Brasília, Ministério do Meio Ambiente, vol. 1, 271p.

Brown, G.E.; J.C. Adrian Jr; E. Smyth; H. Leet \& S. Brennan. 2000. Ostariophysan alarm pheromones: laboratory and field tests of the functional significance of nitrogen oxides. Journal of Chemical Ecology 26 (1): 139-154.

Brown, G.E.; J.C. Adrian Jr; N.T. Naderi; M.C. Harvey \& J.M. Kelly. 2003. Nitrogen oxides elicit antipredator responses in juvenile channel catfish, but not in convict cichlids or rainbow trout: conservation of The ostariophysan alarm pheromone. Journal of Chemical Ecology 29 (8): 1781-1796.

Burks, R.L. \& D.M. Lodge. 2002. Mini review. Cued in: advances and opportunities in freshwater chemical ecology. Journal of Chemical Ecology 28 (10): 1901-1917.

Castro, R.M.C. 1999. Evolução da Ictiofauna de Riachos SulAmericanos: Padrões Gerais e Possíveis Processos Causais, p. 157-182. In: E.P. Caramaschi; R. Mazzoni \& P.R. Peres-Neto (Eds). Ecologia de Peixes de Riachos. Rio de Janeiro, Programa de Pós-Graduação em Ecologia, Universidade Federal do Rio de Janeiro, Oecologia Brasiliensis, vol. 6, XVI+260p.

Castro, R.M.C.; A.C. Ribeiro; R.C. Benine \& A.L.A. Melo. 2003. Lophiobrycon weitzmani, a new genus and species of glandulocaudine fish (Characiformes: Characidae) from the rio Grande drainage, upper rio Paraná system, southeastern Brazil. Neotropical Ichthyology 1 (1): 11-19.

Chivers, D.P. \& R.J.F. Sмith. 1998. Chemical alarm signaling in aquatic predator-prey systems: a review and prospectus. Ecoscience 5 (3): 338-352.

Chivers, D.P.; M.P. Puttlitz \& A.R. Blaustein. 2000. Chemical alarm signaling by reticulate sculpins, Cottus perplexus. Environmental Biology of Fishes 57: 347-352.

Chivers, D.P.; A. Mathis; G.E. Brown; R.S. Mirza \& B.D. Wisenden. 1999. Scratching the skin of predator-prey interactions in fishes: a tribute to R. Jan F. Smith (1940-1998). Environmental Biology of Fishes 56: 343-350.

CSANYI, V. 1985. Ethological analysis of predator avoidance by the paradise fish (Macropodus opercularis L.) 1. Recognition and learning of predators. Behaviour 92: 227-240.

EDmunds, M. 1974. Defense in animals. New York, Longman, XVIII+358p.

Esteves, K.E. \& J. Lobón-Cerviá. 2001. Composition and trophic structure of a fish community of a clear water Atlantic rainforest stream in southeastern Brazil. Environmental Biology of Fishes 62: 429-440.

Ferraris Jr, C.J. \& R.E. Reis. 2005. Preface. Neotropical catfish diversity: an historical perspective. Neotropical Ichthyology 3 (4): 453-454.

FINK, S.V. \& W.L. Fink. 1981. Interrelationships of ostariophysan fishes (Teleostei). Zoological Journal of the Linnean Society 72: 297-353.

FINK, S.V. \& W.L. FINK. 1996. Interrelationships of ostariophysan fishes (Teleostei), p. 209-250. In: M.L.J. Stiassny; L.R. Parenti 
\& G.D. Johnson (Eds). Interrelationships of fishes. San Diego, Academic Press, 496p.

FrIsch, K. VON. 1938. Zür Psychologie des Fisch-Schwarmes. Natürwissenschaften 26 (37): 601-606.

Frisch, K. von. 1941. Die Bedeutung des Geruchsinnes im Leben der Fische Natürwissenschaften 29 (22/23): 321-33.

Gazdewich, K.J. \& D.P. Chivers. 2002. Acquired recognition by fathead minnows: influence of habitat characteristics on survival. Journal of Chemical Ecology 28: 439-445.

Giaquinto, P.C. \& G.L. Volpato. 2005. Chemical cues related to conspecific size in pintado catfish, Pseudoplatystoma coruscans. Acta Ethologica 8: 65-69.

Gould, S.J.G. \& E.S. VRba. 1982. Exaptation - a missing term in the science of form. Paleobiology 8: 4-15.

Gray, J.A.B. \& E.J. Denton. 1991. Fast pressure pulses and communication between fish. Journal of the Marine Biological Association of the United Kingdom 71: 83-106.

Greenwood, P.H.; D.E. Rosen; S.H. Weitzman \& G.S. Myers. 1966. Phyletic studies of teleostean fishes with a provisional classification of living forms. Bulletin of the American Museum of Natural History 131: 339-455.

Heczko, J. \& B.H. Seghers. 1981. Effects of alarm substance on schooling in the common shiner (Notropis cornutus, Cyprinidae). Environmental Biology of Fishes 6 (1): 25-9.

Hews, D.K. 1988. Alarm response in larval western toads, Bufo boreas: release of larval chemicals by a natural predator and its effect on predator capture efficiency. Animal Behaviour 36: $125-33$.

Hoare, D.J.; Couzin, I.D.; Godin, J.-G.J. \& J. Krause. 2004. Contextdepende group size choice in fish. Animal Behaviour 67: 155-164.

Howe, N.R. \& Y.M. SHeikн. 1975. Anthopleurine: a sea anemone alarm pheromone. Science 189: 386-389.

Hurlbert, S.H. 1978. The measurement of niche overlap and some relatives. Ecology 59: 66-77.

Ingenito, L.F.S.; L.F. Duboc \& V. AвilhoA. 2004. Contribuição ao conhecimento da ictiofauna da bacia do alto rio Iguaçu, Paraná, Brasil. Arquivos de Ciências Veterinárias e Zoologia da UNIPAR 7 (1): 23-36.

Irving, P.W. \& A.E. Magurran. 1997. Context-dependent fright reactions in captive minnows: the importance of naturalness in laboratory experiments. Animal Behaviour 53: 11931201.

JAKOBSEn, J. \& G.H. Johnsen. 1989. The influence of alarm substance on feeding in zebra danio fish (Brachydanio rerio). Ethology 82: 325-327.

Johnson, L.K.; L.W. Haynes; M.A. Carlson; H.A. Fortnum \& D.L. Gorgas. 1985. Alarm substances of the stingless bee, Trigona silvestriana. Journal of Chemical Ecology 11: 409-416.

JONES R.H. 1993. Longitudinal data with serial correlation: a state-space approach. London, Chapman-Hall, XI+225p.

Keenleyside, M.H.A. 1955. Some aspects of the schooling behaviour of fish. Behaviour 8: 183-249.
Krause, J. \& R.W. Tegeder. 1994. The mechanism of aggregation behaviour in fish shoals: individuals minimize approach time to neighbours. Animal Behaviour 48: 353-359.

KreBs, C.J. 1998. Ecological Methodology. Menlo Park, Addison Wesley Longman, $2^{\text {nd }}$ ed., XII+620p.

LAIRD, N.M. \& J.H. WARE. 1982. Random effects models for longitudinal data. Biometrics 38: 963-974.

Lampert, V.R.; M.A. Azevedo \& C.B. Fialho. 2003. Hábito alimentar de Mimagoniates microlepis Steindachner, 1876 (Characidae: Glandulocaudinae) do canal de ligação entre as lagoas Emboaba e Emboabinha, Osório, RS. Comunicações do Museu de Ciências e Tecnologia da PUCRS, Série Zoologia, 16 (1): 3-16.

Lauder, G.V. \& K.F Liem. 1983. The evolution and interrelationships of the actinopterygian fishes. Bulletin of the Museum of Comparative Zoology 150 (3): 95-197.

Lemly, A.D. \& R.J.F. Smith. 1985. Effects of acute exposure to acidified water on the behavioral response of fathead minnows, Pimephales promelas, to chemical feeding stimuli. Aquatic Toxicology 6: 25-36.

Lemly, A.D. \& R.J.F. SMith. 1986. A behavioral assay for assessing effects of pollutants on fish chemoreception. Ecotoxicology and Environmental Safety 11: 210-8.

Lemly, A.D. \& R.J.F. Smith. 1987. Effects of chronic exposure to acidified water on chemorreception of feeding stimuli in fathead minnows Pimephales promelas: mechanisms and ecological implications. Environmental Toxicology and Chemistry 6: 225-38.

Lowe-McConnelL, R.H. 1987. Ecological studies in tropical fish communities. Cambridge Tropical Biology Series. Cambridge, Cambridge University Press, XIV+386.

Machado, A.B.M.; C.S. Martins; G. M. Drummond \& F. Sebaio. 2005. Lista da fauna brasileira ameaçada de extinção: incluindo as listas das espécies quase ameaçadas e deficientes em dados. Belo Horizonte, Fundação Biodiversitas, $157 \mathrm{p}$.

Madison, D.M.; A.M. Sullivan; J.C. Maerz; J.H. McDarby, \& J.R. RoHr. 2002. A complex, cross-taxon, chemical releaser of antipredator behavior in amphibians. Journal of Chemical Ecology 28 (11): 2271-2282.

MagurRan, A.E. 1990. The adaptative significance of schooling as an anti-predator defense in fish. Annales Zoologici Fennici 27 (2): 51-66.

Magurran, A.E. \& T.J. Pitcher. 1987. Provenance, shoal size and the sociobiology of predator-evasion behaviour in minnow shoals. Proceedings of the Royal Society of London. Series B, Biological Sciences 229: 439-465.

Magurran, A.E.; P.W. Irving \& P.A. Henderson. 1996. Is there a fish alarm pheromone? A wild study and critique. Proceedings of the Royal Society of London. Series B, Biological Sciences 263: 1551-1556.

Marvin, G.A.; R.R. Whitekiller. \& V.H. Hutchison. 2004. Avoidance of alarm chemicals by plethodontid salamanders (genus 
Eurycea): importance of phylogeny, ecology, and methodology. Herpetologica 60 (1): 24-33.

Mathis, A. \& R.J.F. Smith. 1992. Avoidance of areas marked with a chemical alarm substance by fathead minnows (Pimephales promelas) in a natural habitat. Canadian Journal of Zoology 70: 1473-1476.

Mathis, A. \& R.J.F. SмITH. 1993. Intraspecific and cross-superorder responses to chemical alarm signals by brook stickleback. Ecology 74: 2395-2404.

Mazzoni, R. \& R. Iglesias-Rios. 2002. Distribution pattern of two fish species in a coastal stream in southeast Brazil. Brazilian Journal of Biology 62 (1): 171-178.

Mazzoni, R. \& C.F. Rezende. 2003. Seasonal diet shift in a Tetragonopterinae (Osteichthyes, Characidae) from the Ubatiba River, RJ, Brazil. Brazilian Journal of Biology 63 (1): 69-74.

Menezes, N.A. \& S.H. Weitzman. 1990. Two new species of Mimagoniates (Teleostei: Characidae: Glandulocaudinae), their phylogeny and biogeography and a key to the glandulocaudin fishes of Brazil and Paraguay. Proceedings of the Biological Society of Washington 103 (2): 380-426.

MirzA, R.S. \& D.P. Chivers. 2002. Brook char (Salvelinus fontinalis) can differentiate chemical alarm cues produced by different age/size classes of conspecifics. Journal of Chemical Ecology 28 (3): 555-564.

Mirza, R.S.; S.A. Fisher \& D.P. Chivers. 2003. Assessment of predation risk by juvenile yellow perch, Perca flavescens: Responses to alarm cues from conspecifics and prey guild members. Environmental Biology of Fishes 66: 321-327.

Moyle, P.B. \& J.J. СесH JR. 1988. Fishes: an introduction to ichthyology. Englewood Cliffs, Prentice Hall, $2^{\text {nd }}$ ed., $\mathrm{XIV}+559 \mathrm{p}$.

NeLson, K. 1964. Behaviour and morphology in the glandulocaudine fishes (Ostariophysi, Characidae). University of California Publications in Zoology 75 (2): 59-152.

Nelson, J.S. 2006. Fishes of the world. Hoboken, John, Wiley and Sons, $4^{\text {th }}$ ed., 624p.

Nordell, S.E. 1998. The response of female guppies, Poecilia reticulata, to chemical stimuli from injured conspecifics. Environmental Biology of Fishes 51: 331-338.

PARTRIDGE, B.L. 1982. The structure and function of fish schools. Scientific American 246 (6): 114-123.

Pfeiffer, W. 1960. Über die Schreckreaktion bei Fischen und die herkunft des Schreckstoffes. Zeitschrift für Vergleichende Physiologie 43: 578-614.

Pfeiffer, W. 1962. The fright reaction of fish. Biological Reviews 37: 495-511.

Pfeiffer, W. 1963a. Alarm Substances. Experientia 19 (3): 113168.

Pfeiffer, W. 1963b. Vergleichende Untersuchungen über die Schreckreaktion und den Schreckstoff der Ostariophysen. Zeitschrift für Vergleichende Physiologie 47: 111-147.

Pfeiffer, W. 1966. Die Schreckreaktion der Fische und Kaulquappen Natürwissenschaften 53 (22): 566-570.
Pfeiffer, W. 1967. Schreckrektion und Schreckstoffzellen bei Ostariophysi und Gonorhynchiformes. Zeitschrift für Vergleichende Physiologie 56: 380-396.

Pfeiffer, W. 1974. Pheromones in fish and amphibian, p. 269296. In: M.C. BIRCH (Ed.). Pheromones. Frontiers of biology. Amsterdam, Elsevier, North-Holland Publishers, vol 32, 495p.

Pfeiffer, W. 1977. The distribution of fright reaction and alarm substance cells in fishes. Copeia 1977 (4): 653-65.

Pfeiffer, W. 1982. Chemical signals in communication, p. 307326. In: T.J. HARA (Ed.). Chemoreception in Fishes. Amsterdam, Elsevier Scientific Publishing, 433p.

Pfeiffer, W.; G. Riegelbauer; G. Meier \& B. Scheibler. 1985. Effect of Hypoxanthine-3(N)-oxide and Hypoxanthine- $(N)$-oxide on central nervous excitation of the black tetra Gymnocorymbus ternetzi (Characidae, Ostariophysi, Pisces) indicated by dorsal light response. Journal of Chemical Ecology 11 (4): 507-523.

Pitcher, T.J. \& A.E. Magurran. 1983. Shoal size, patch profitability and information exchange in foraging goldfish. Animal Behaviour 31 (2): 546-555.

Pitcher, T. J. \& J.K. PARrish. 1993. Functions of shoaling behaviour in teleosts, p. 363-439. In: Behaviour of teleost fishes. London, Chapman and Hall, $2^{\text {nd }}$ ed., XX+718p.

Radakov, D.V. 1973. Schooling in the ecology of fish. New York, Halsted Press, John Wiley and Sons, 173p.

Ragusa-NetTo, J. 2000. Raptors and "campo-cerrado" bird mixed flock led by Cypsnagra hirundinacea (Emberizidae: Thraupinae). Revista Brasileira de Biologia 60 (3): 461-467.

REED, J.R. 1969. Alarm substances and fright reaction in some fishes from the southeastern United States. Transactions of the American Fisheries Society 98: 664-668.

Reis, R.E.; S.O. Kullander \& C.J. Ferraris JR. 2003. Check List of the freshwater fishes of South and Central America. Porto Alegre, EDIPUCRS, 7429p.

Rosen, D.E. \& P.H. Greenwood. 1970. Origin of the Weberian Apparatus and the relationships of the ostariophysan and gonorynchiform fishes. American Museum Novitates 2428: $1-25$.

Sabino, J. \& R.M.C. Castro. 1990. Alimentação, período de atividade e distribuição espacial dos peixes de um riacho da Floresta Atlântica (Sudeste do Brasil). Revista Brasileira de Biologia 50 (1): 23-36.

Sant'Anna, J.F.M; M.A. Almeida; M.R. Vicari; O.A. Shibatta \& R.F. ARTONI. 2006. Levantamento rápido de peixes em uma lagoa marginal do rio Imbituva na bacia do alto rio Tibagi, Paraná, Brasil. Publicatio Universidade Estadual de Ponta Grossa, Ciências Biológicas e da Saúde, 12 (1): 39-46.

Schultz, H. 1959. The Mimagoniates species. Tropical Fish Hobbyist 7: 46-53.

Schutz, F. 1956. Vergleichende Untersuchungen über die Schreckreaktion bei Fischen und deren Verbreitung. Zeitschrift für Vergleichende Physiologie 38: 84-135.

Sherman, P.W. 1977. Nepotism and the evolution of alarm calls. 
Science 197: 1246-53.

SIEGEL, S. 1975. Estatística não-paramétrica (para as ciências do comportamento). Rio de Janeiro, McGraw-Hill, $\mathrm{XX}+350 \mathrm{p}$.

Singer, J.M. \& D.F. Andrade. 1986. Análise de dados longitudinais. Campinas, Unicamp, 106p.

SмITH, R.J.F. 1973. Testosterone eliminates alarm substance in male fathead minnows. Canadian Journal of Zoology 51: 875-6.

SMITH, R.J.F. 1976. Male fathead minnows (Pimephales promelas Rafinesque) retain their fright reaction to alarm substance during the breeding season. Canadian Journal of Zoology 54 (12): 2230-2231.

SмITH, R.J.F. 1977. Chemical communication as adaptation: alarm substance of fish, p. 303-320. In: D. Muller-Schwarze \& M.M. Mozell (Eds). Chemical Signals in Vertebrates. New York, Plenum Publishing. 609p.

SMITH, R.J.F. 1979. Alarm reaction of Iowa and Johnny darters (Etheostoma, Percidae, Pisces) to chemicals from injured conspecifics. Canadian Journal of Zoology 57: 1278-82.

SMITH, R.J.F. 1981. Effect of food deprivation on the reaction of Iowa darters (Etheostoma exile) to skin extract. Canadian Journal of Zoology 59 (3): 558-60.

SMITH, R.J.F. 1982. The adaptive significance of the alarm substance - fright reaction system, p. 327-342. In: T.J. HARA. Chemoreception in Fishes. Amsterdam, Elsevier Scientific Publishing, 433p.

Sмith, R.J.F. 1983. Seasonal loss of alarm substance cells in Chrosomus neogaeus, Notropis venustus and N. whipplei. Copeia 1983 (3): 822-826.

SMITH, R.J.F. 1986. The evolution of chemical alarm signals in fishes, p. 99-115. In: D. Duvall \& R.M. Silverstein. Chemical signals in vertebrates 4: ecology, evolution and comparative biology. New York, Plenum Publishing, 754p.

Sмith, R.J.F. 1992. Alarm signals in fishes. Reviews in Fish Biology and Fisheries 2: 33-63.

SMith, R.J.F. \& B.J. LAWRENCE. 1988. Effects of acute exposure to acidified water on the behavioral response of fathead minnows, Pimephales promelas, to alarm substance (Schreckstoff). Environmental Toxicology and Chemistry 7: 329-35.

Smith, R.J.F. \& J.D. Sмiтн. 1983. Seasonal loss of alarm substance cells in Chrosomus neogaeus, Notropis venustus and $N$. whipplei. Copeia 1983 (3): 822-826.

SMith, J.D. \& R.J.F. SMiTH. 1986. Effect of hormone treatments on alarm substance cell counts in the pearl dace, Semotilus margarita. Canadian Journal of Zoology 64: 291-5.

Verheijen, F.J. 1956. Transmission of a flight reaction amongst a school of fish and the underlying sensory mechanisms.
Experientia 12 (5): 202-204.

Volpato, G.L.; A. Castro; E.G. Freitas; P.C. Giaquinto; M.F. CASTilho; E.M.P. dA Silva \& L.C. Jordão. 2006. Comunicação química em peixes, p. 15-51. In: J.E.P. Cyrino \& E.C. URbINATI. (Eds.). Tópicos especiais em biologia aquática e aqüicultura. Jaboticabal, Sociedade Brasileira de Aqüicultura e Biologia Aquática, 293p.

WALDMAn, B. 1982. Quantitative and developmental analysis of the alarm reaction in the Zebra Danio, Brachydanio rerio. Copeia 1982 (1): 1-9.

Weitzman, S.H. \& S.V. Fink. 1985. Xenurobryconin phylogeny and putative pheromone pumps in Glandulocaudine fishes (Teleostei: Characidae). Smithsonian Contributions to Zoology 421: 1-121.

Weitzman, S.H. \& L.R. Malabarba. 1998. Perspectives about the phylogeny and classification of the Characidae (Teleostei: Characiformes), p. 161-170. In: L.R. Malabarba; R.E. Reis; R.P. VARI; Z.M.S. LuCENA \& C.A.S. LuCEnA (Eds). Phylogeny and classification of Neotropical fishes. Porto Alegre, EDIPUCRS, $\mathrm{X}+603 \mathrm{p}$.

Weitzman, S.H. \& N.A. Menezes. 1998. Relationships of the tribes and genera of the Glandulocaudinae (Ostariophysi: Characiformes: Characidae) with a description of a new genus, Chrysobrycon, p. 171-192. In: L.R. MaLABARBA; R.E. ReIs; R.P. VARI; Z.M.S. Lucena \& C.A.S. LuCENA (Eds). Phylogeny and classification of Neotropical fishes. Porto Alegre, EDIPUCRS, X+603p.

Weitzman, S.H. \& R.P. VARI. 1988. Miniaturization in South American freshwater fishes; an overview and discussion. Proceedings of the Biological Society of Washington 101 (2): 444465.

Weitzman, S.H.; N.A. Menezes \& M.J. Weitzman. 1988. Phylogenetic biogeography of the Glandulocaudini (Teleostei: Characiformes, Characidae) with comments on the distributions of other freshwater fishes in Eastern and Southeastern Brazil, p. 379-428. In: P.E. Vanzolini \& W.D. Heyer. Proceedings of a Workshop on Neotropical Distribution Patterns. Rio de Janeiro, Academia Brasileira de Ciências, 488p.

Wisenden, B.D. \& T.A. Thiel. 2002. Field verification of predator attraction to minnow alarm substance. Journal of Chemical Ecology 28: 433-438.

Wisenden, B.D.; D.P. Chivers; G.E. Brown \& R.J.F. Smith. 1995. The role of experience in risk assessment: avoidance of areas chemically labelled with fathead minnow alarm pheromone by conspecifics and heterospecifics. Écoscience 2: 115-122.

Wisenden, B.D.; K.A. Vollbrecht \& J.L. Brown. 2004. Is there a fish alarm cue? Affirming evidence from a wild study. Animal Behaviour 67: 59-67.

Recebido em 28.VI.2007; aceito em 30.XI.2007. 